\title{
¿Lifecycle of a Submesoscale Front Birthed from a Nearshore Internal Bore $\mathscr{O}$
}

\author{
Sean R. Haney, ${ }^{\mathrm{a}}$ Alexandra J. Simpson, ${ }^{\mathrm{b}}$ Jacqueline M. McSweeney, ${ }^{\mathrm{b}}$ Amy F. Waterhouse, ${ }^{\mathrm{a}}$

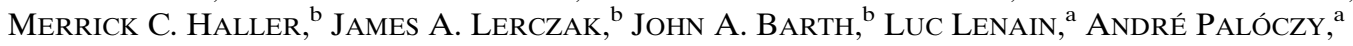 \\ KATE ADAMS, ${ }^{\mathrm{c}}$ AND JENNIFER A. MACKINNON ${ }^{\mathrm{a}}$ \\ ${ }^{\text {a }}$ Scripps Institution of Oceanography, University of California, San Diego, La Jolla, California \\ ${ }^{\mathrm{b}}$ Oregon State University, Corvallis, Oregon \\ ${ }^{\mathrm{c}}$ Naval Information Warfare Center Pacific, San Diego, California
}

(Manuscript received 18 March 2021, in final form 26 July 2021)

\begin{abstract}
The ocean is home to many different submesoscale phenomena, including internal waves, fronts, and gravity currents. Each of these processes entails complex nonlinear dynamics, even in isolation. Here we present shipboard, moored, and remote observations of a submesoscale gravity current front created by a shoaling internal tidal bore in the coastal ocean. The internal bore is observed to flatten as it shoals, leaving behind a gravity current front that propagates significantly slower than the bore. We posit that the generation and separation of the front from the bore is related to particular stratification ahead of the bore, which allows the bore to reach the maximum possible internal wave speed. After the front is calved from the bore, it is observed to propagate as a gravity current for approximately $4 \mathrm{~h}$, with associated elevated turbulent dissipation rates. A strong cross-shore gradient of alongshore velocity creates enhanced vertical vorticity (Rossby number $\approx 40$ ) that remains locked with the front. Lateral shear instabilities develop along the front and may hasten its demise.
\end{abstract}

KEYWORDS: Ocean; Continental shelf/slope; Ageostrophic circulations; Density currents; Diapycnal mixing; Frontogenesis/frontolysis; Fronts; Gravity waves; Inertia-gravity waves; Instability; Internal waves; Mixing; Nonlinear dynamics; Turbulence

\section{Introduction}

The inner continental shelf is home to a variety of lively phenomena, from wind-driven flows to nonlinear internal tides, to jets and fronts, to submesoscale instabilities, to surface and bottom boundary layers, to energetic turbulence (Kumar et al. 2021). Together these processes govern the distribution of heat, freshwater, momentum, pollutants, and biologically essential nutrients (Boehm et al. 2017). Most work to date has explored the dynamical underpinnings of each of these phenomena relatively independently; they are then superimposed in conceptual schematics (e.g., Lentz and Fewings 2012) and model parameterizations (Burchard et al. 2008; Klingbeil et al. 2018). In particular, theoretical treatment and conceptual models of submesoscale instabilities, jets, and fronts have mostly evolved directly from the treatment of instabilities of mesoscale currents (McWilliams 2016). In parallel, studies of

D Denotes content that is immediately available upon publication as open access.

Supplemental information related to this paper is available at the Journals Online website: https://doi.org/10.1175/JPO-D-21-0062.s1.

Haney: Deceased.

Palóczy's current affiliation: Department of Geosciences, University of Oslo, Oslo, Norway.

Corresponding author: Jennifer A. MacKinnon, jmackinnon@ ucsd.edu internal wave generation, evolution, and dissipation are often conceptualized in an ocean in which background currents play, at most, a passive role by steering wave propagation (Lee and Beardsley 1974; Stastna and Lamb 2002). However, it is increasingly clear that internal waves and submesoscale features occupy similar length and time scales, and thus may interact in modestly or even strongly nonlinear ways (e.g., Thomas 2017).

Here we present a novel example of a near-surface submesocale front, with some characteristics of a buoyant gravity current, that appears to be generated by a shoaling nonlinear internal bore. Before presenting our observations and discussing their interpretation, we motivate the present study by briefly reviewing the context for internal tidal bores, sharp fronts, and gravity currents.

Internal tides are found throughout the coastal oceans globally and are frequently observed propagating onshore from the shelf-break (Ramp et al. 2004; Scotti et al. 2007; Kelly and Nash 2010; Suanda and Barth 2015). Dynamically, internal waves involve interplay between baroclinic density/pressure forces, buoyancy forces in stratified water, and Coriolis, which combine to propagate a wave forward (Gill 1982). As internal tides propagate into shallower water depths, wave amplitude grows, as does the role of the quadratic advective term in the momentum equation, and the tides often develop a nonlinear character. Their nonlinear evolution can lead to various internal wave shapes, including steep bores, undular internal waves (or trains of high-frequency waves), and solitary internal waves (i.e., solitons). The details of how these internal waves evolve depend on their amplitude and waveguide factors, such as the ambient stratification, background currents, and total water depth (Vlasenko and Hutter 2002; Stastna and Lamb 2002; Scotti 
et al. 2008; McSweeney et al. 2020a). Previous analyses of the mooring data presented in this paper provide insight about the regional internal wave field (McSweeney et al. 2020a,b). Large-amplitude internal bores propagate into the region approximately every $6 \mathrm{~h}$, possibly due to the presence of multiple generation sites or the formation of multiple bores within a shoaling semidiurnal internal tide (Lamb 1994; Grimshaw et al. 2014; McSweeney et al. 2020a).

Some of the internal bores observed in the region described by McSweeney et al. (2020a) become nonlinear enough that their leading isopycnals outcrop (Figs. 5, 11, and 12 in McSweeney et al. 2020a), a behavior that has also been observed for shoaling internal bores at other sites (Scotti and Pineda 2004; Thomas et al. 2016; Walter et al. 2016). The initial steep wave front is often followed by trailing highfrequency waves. The overall shape, and detailed partition into a steep bore plus high-frequency waves, evolves substantially as the waves shoal between the 100- and $10-\mathrm{m}$ isobaths (McSweeney et al. 2020a,b). The specific evolution of bore shape largely depends on the stratification ahead of a bore and the vertical position of the pycnocline-water column characteristics that are equally influenced by subtidal modulation and higher-frequency variability from the frequent passage of the internal bores. The nonlinear shoaling dynamics of internal tides play an important role in providing the power for and setting the cross-shelf and vertical patterns of enhanced turbulent mixing (MacKinnon and Gregg 2003; Moum et al. 2003a; Shroyer et al. 2010; Grimshaw et al. 2010; Becherer et al. 2020).

At the same time, a parallel life cycle exists that links mesoscale (often wind-driven) large-scale currents, submesoscale instabilities at their edges, and sharp and often turbulent fronts. Near the ocean surface, submesoscale fronts are often created through confluent flow (Stone 1966; Hoskins 1974; Mahadevan and Tandon 2006; McWilliams 2016). Though secondary circulations act to steepen the front through frontogenesis, in this process rotation still plays an order one role, balancing the pressure gradient force. As horizontal scales shrink, the importance of rotation fades. Warner et al. (2018) observe fronts on the edges of tropical instability waves, created through confluence. As the fronts steepen (and in their case moves closer to the equator where Coriolis weakens), the dynamical balance switches to that of a propagating gravity current, with baroclinic pressure and nonlinear advection being the first-order terms. Similarly, Pham and Sarkar (2018) simulate a density front that initially is in thermal wind balance. The secondary circulations that develop as part of frontogenesis become strong enough to switch it into the regime of propagating gravity current. Although gravity currents are more well known from river outflows (e.g., Nash et al. 2005; Jurisa et al. 2016; Solodoch et al. 2020), these examples show that other frontogenetic processes can ultimately end with unbalanced gravity currents as well. Recent work by Barkan et al. (2019) explores the theoretical motivation by which "runaway" frontogenesis forgets the context that provided the initial instigation, with similar end-stage unbalanced situations arising from multiple initial situations.
These two dynamical pathways [1) steepening internal tides and 2) submesoscale fronts and gravity currents] are generally treated separately, but here we present observations of nonlinear internal bores, fronts and gravity currents occupying the same space and time scales, which results in energy passing from one to the other. There is a limited body of previous work considering this type of interaction. White and Helfrich (2012) explore the coexistence of, and interactions between, gravity currents and internal bores, using a combination of hydraulic control theory and numerics. Their work provides a useful framework for interpreting our observations and is discussed in more detail below.

The observations presented here were collected as part of the Office of Naval Research Inner Shelf Dynamics Experiment (ISDE) (Lerczak et al. 2019; Kumar et al. 2021). The overall project was designed to explore the superposition, intersection, and interactions between a wide range of inner-shelf phenomena (Kumar et al. 2021). Here we utilize shipboard, mooring, and remote sensing data to detail the generation of a gravity current front from a shoaling internal bore and the front's subsequent evolution and destruction.

\section{Methods}

The ISDE was a large, coordinated field program that collected both in situ and remote sensing observations in combination with numerical modeling over a $50-\mathrm{km}$ stretch of coast in the vicinity of Point Sal, California (Lerczak et al. 2019). The experiment occurred from late August to early November 2017 (with a pilot experiment in 2015; Colosi et al. 2018) in water depths ranging from 5 to $150 \mathrm{~m}$. The field campaign included moored time series measurements, ship and small boat surveys, surface drifters, and remote sensing from land, airplanes, and space [see Kumar et al. (2021) and Waterhouse et al. (2020) for more information]. The observations described herein are a subset of ISDE observations, obtained on 15 September 2017.

Shipboard observations of the front discussed here were obtained in coordinated shipboard sampling from the R/Vs Sally Ride, Oceanus, and Sproul from 0000 to 0600 UTC 15 September 2017. Our analysis includes data from the flowthrough temperature sensors ( $\sim 5 \mathrm{~m}$ below the surface) on each ship and a 20-m-long towed bow chain deployed on the Ride. The bow chain was designed to measure undisturbed nearsurface horizontal and vertical temperature gradients, and included a combination of $16 \mathrm{RBR}$, Ltd, Solo instruments (temperature, sampling at $2 \mathrm{~Hz}$ ) mounted every $1 \mathrm{~m}$ along the bow chain line, interspersed with 3 RBR Concerto instruments (temperature, pressure, and conductivity, sampling at $12 \mathrm{~Hz}$ ) at 5,10 , and $15 \mathrm{~m}$ along the line. From the three pressure sensors, the shape of the bow chain catenary is calculated at each time step and is used to interpolate temperature onto constant pressure surfaces.

We also analyze in situ, profiling data from the R/V Ride, which were collected via profiles from the stern of the ship that alternated between a microstructure profiler (Rockland Scientific International, Inc., VMP-250, with shear probes, Thermometrics FP07 thermistors, and a CTD), and an RBR Concerto CTD. Because of ship-wake contamination, the upper $10 \mathrm{~m}$ of the VMP profiles were discarded. The 

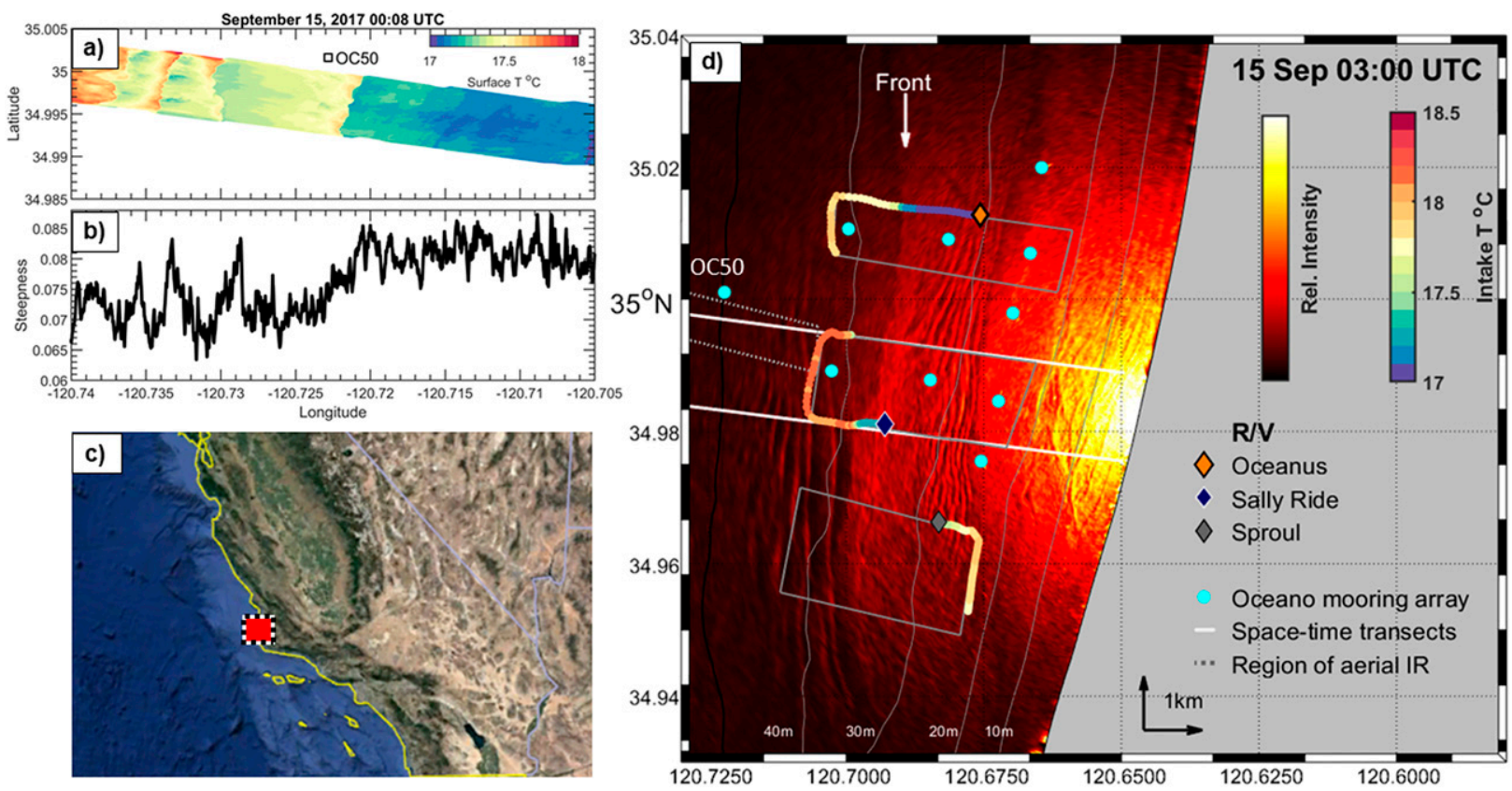

FIG. 1. (a) Sea surface temperature and (b) surface wave steepness from the airborne MASS. (c) Map of the California coast; the red box corresponds to the approximate region shown in (d). (d) Radar snapshot with synchronous ship locations and sampling tracks (gray lines). Temperature contrails (measured approximately $6 \mathrm{~m}$ below the ocean surface from the thermosalinograph flowthrough system) behind the ship locations span the previous $1.75 \mathrm{~h}$. Note that (a) and (b) are from a different time than this snapshot. Also, mooring locations are shown as cyan dots, cross-shore transects for the radar space-time diagrams (Fig. 2) are shown as white lines, and the sea surface temperature partial footprint [(a)] is shown as dotted white lines. This is a single frame from the movie provided in the online supplemental material.

turbulent dissipation rate was calculated following Lueck (2013). Turbulent heat fluxes were calculated from simultaneous turbulence and temperature profile data following standard techniques (e.g., Adams et al. 2019).

Ocean velocity during the R/V Ride surveys was measured with a hull-mounted $300-\mathrm{kHz}$ ADCP and side-pole mounted 5-beam 500-kHZ ADCP (with 3-m vertical bins, sampling at $1 \mathrm{~Hz}$ ). These two ADCPs allowed for sampling of water column velocity from $\sim 3-5 \mathrm{~m}$ nearly to the bottom; sidelobe reflections contaminate the bottom $15 \%$ of the water column. Acoustic backscatter was measured with a Biosonics, Inc., echosounder (with 120- and $200-\mathrm{kHz}$ transducers) mounted in the hull on the R/V Ride.

A subset of the ISDE mooring array is used in this analysis, including the OC50, OC40(N,S), OC32(N,S), and OC25(SA, $\mathrm{SB}, \mathrm{M}, \mathrm{NB}, \mathrm{NA})$ moorings that span a depth range of $25-50 \mathrm{~m}$ (cyan dots in Fig. 1d; numbers in the mooring names indicate water depth). These include velocity data from a bottommounted ADCP [with transducer frequency of $500 \mathrm{kHz}$ for OC50 and OC40(S,N) and $1000 \mathrm{kHz}$ for OC25(SA, SB, M, $\mathrm{NB}, \mathrm{NA})$ ], water-column temperature data every $1-3 \mathrm{~m}$, and some salinity data. The $32 \mathrm{~m}$ moorings are the only moorings without ADCP data. Further details about these moorings can be found in McSweeney et al. (2020a) and McSweeney et al. (2020b).

A land-based radar, deployed onshore of the mooring array, complemented the in situ observations. The radar collected observations of propagating internal waves and surface fronts over a footprint of $10-\mathrm{km}$ radius with a resolution of $3 \mathrm{~m}$ in range and $1^{\circ}$ in azimuth. The raw image sampling rate was approximately $0.7 \mathrm{~Hz}$. Two-minute "wave averaging" of the raw radar images removes the surface gravity wave signals and enhances the imaging of slower features with longer time scales. The internal waves and fronts are imaged as bright and dark bands due to changes in surface roughness in regions of surface current convergence and divergence, respectively; an example image is shown in Fig. 1d, which is one frame of the wave-averaged radar movie (which also includes shipboard data) that is provided in the online supplemental material. Further information on the radar system and deployment can be found in Haller et al. (2019).

Airborne remote sensing measurements were collected using the Modular Aerial Sensing System (MASS; Melville et al. 2016) to characterize the properties of surface and internal wave processes in the ISDE sampling region. The instrument package includes infrared, visible, and hyperspectral cameras and a highresolution long-range scanning lidar (Lenain et al. 2019).

\section{Results}

A sharp temperature front was observed off the California coast through multiple ship crossings and remote sensing. Figure 1 shows a sea surface temperature front (warm 
a) North Transect (Ride transiting offshore)

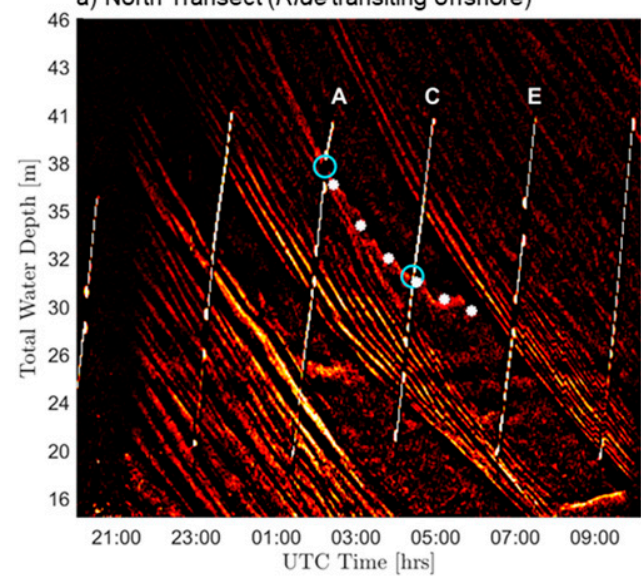

b) South Transect (Ride transiting onshore)

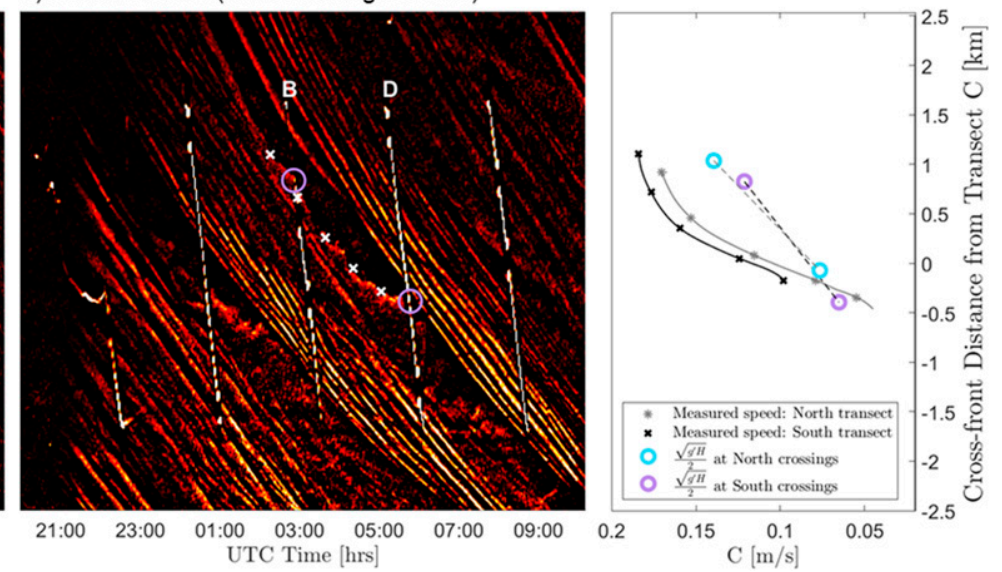

FIG. 2. (a) Radar space-time diagram extracted along the northern (offshore) R/V Sally Ride transit (shown in Fig. 1). The R/V Ride front crossings are indicated as open cyan circles. The analyzed front is marked with white asterisks; note that there is a similar front approximately $6 \mathrm{~h}$ earlier. (b) As in (a), but extracted along the southern (offshore) transit. R/V Ride front crossings are indicated as open purple circles. The analyzed front is marked with white crosses; the earlier, similar front is also visible. In (a) and (b), the R/V Ride's signature in the radar is visible as linear white streaks. Transects are labeled A-E corresponding to the transects in Fig. 5, below. (c) Estimates of the front's cross-shore speed from the radar front tracking in (a) and (b), shown as gray and black lines, respectively. Theoretical estimates of gravity current speed computed from the R/V Ride frontal data are shown as dashed lines.

offshore and cool onshore; labeled "front" in Fig. 1d) along with multiple ship tracks. This front is aligned roughly alongshore (north/south) and is propagating shoreward. Note that the temperature contrails represent $1.75 \mathrm{~h}$ of data whereas the radar image is a snapshot. Hence, the temperature transitions observed earlier in the ship tracks may no longer line up with the features observed in the radar. The front in the radar image is visible over a distance of $\sim 8 \mathrm{~km}$ in the alongshore direction. This snapshot is one frame of the movie that is included in the online supplemental material.

Aerial infrared imagery (Fig. 1a) gives another view of the same front but at an earlier time. The sharpest temperature gradient is centered near $120.722^{\circ} \mathrm{W}$ in the infrared data. Sea surface temperature (SST) collected from the MASS (Fig. 1a) highlights the sharpness of the front and the presence of highfrequency trailing waves behind the main front. Surface gravity wave steepness $S=\left[(\partial \eta / \partial x)^{2}+(\partial \eta / \partial y)^{2}\right]^{1 / 2}$ computed from the MASS-derived surface topography $\eta(x, y)$ shows the energetic surface wave-current interaction that occurs as the front propagates onshore (Fig. 1b). We find an unmodulated surface wave field on the cold, shoreward side of the front, and modulation of the wave steepness by the front on the offshore side. The surface waves and front propagating in the same direction lead to surface smoothing (lower steepness), whereas localized roughening is associated with the presence of trailing waves where currents and surface gravity are opposed (locally) and cause the rapid steepening of surface waves [see Lenain and Pizzo (2021) for details].

\section{a. Cross-shore propagation}

To understand the nature of this feature, we first look at the evolution in time and space from the land-based radar observations. A convenient method for observing the propagation of sharp near-surface features is a space-time (Hovmöller) diagram.
Figures 2 and 3 show space-time diagrams of radar intensity extracted along the cross-shore transects indicated by white lines in Fig. 1d and in the video in the online supplemental material, which align with the northern offshore (Figs. 2a, 3a) and southern onshore (Figs. 2b, 3b) transits of the R/V Ride. Figure 3 is a zoomed-in and annotated version of the data in Fig. 2 to highlight the stages of the front's evolution. The signature of the R/V Ride picked up by the radar is visible as white streaks with ship transits labeled A-E in Fig. 2; gaps in the streaks indicate times in which the ship veers off the transect line, potentially due to surface velocity gradients.

The dominant feature is the cross-shore propagation of nonlinear internal waves, visible as yellow-orange, nearly linear, negatively sloping streaks that indicate their shoreward propagation. It is especially evident in Fig. 2 that the internal waves tend to arrive in packets, with the leading internal tidal bore arriving first followed by a quiet (dark) period and then a high-frequency packet of internal waves. These propagating waves all have a similar cross-shore speed, consistent with nonlinear internal wave propagation (McSweeney et al. 2020a).

The event of interest here is a slower feature that peels off of the middle group of waves, which we are referring to as a detached front. This feature is crossed multiple times by the $\mathrm{R} / \mathrm{V}$ Ride ship track, with the intersections denoted by cyan circles (offshore crossings) and purple circles (onshore crossings) in Fig. 2. The front begins to detach after the ship crossings labeled "A" and " $\mathrm{B}$ " in Figs. $2 \mathrm{a}$ and $2 \mathrm{~b}$, and is fully detached by crossings " $C$ ", and "D." Detailed labels of this life cycle are given in Fig. 3. As apparent by its shallower slope in the space-time diagram, this detached front feature propagates appreciably more slowly than the internal wave speed exhibited by the vast majority of wave packet members, and instead propagates at close to the speed expected 

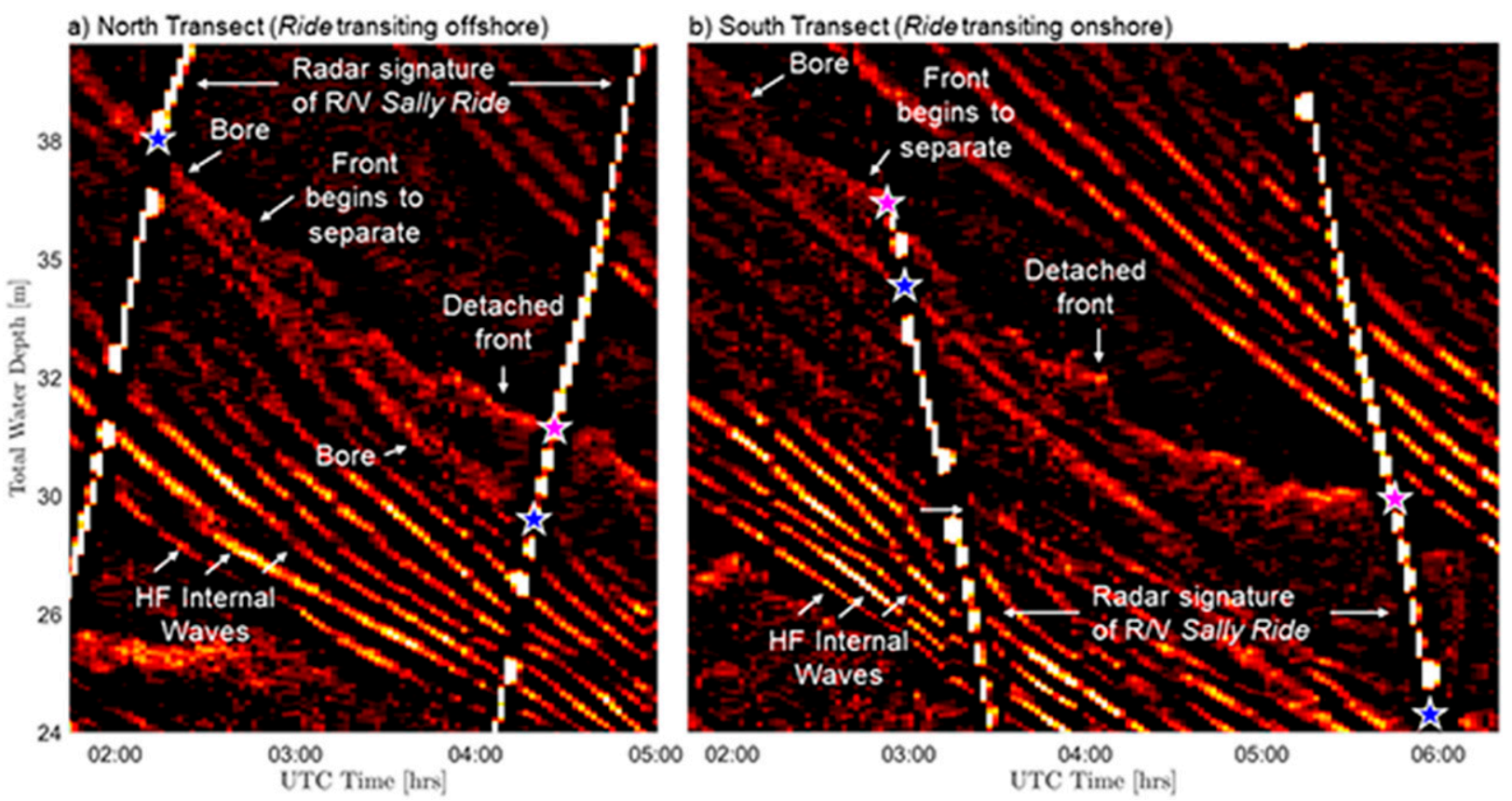

FIG. 3. (a) Radar space-time diagram extracted along the northern (offshore) R/V Sally Ride transit (shown in Fig. 1). The ship's radar signature is visible as a bright line. As also indicated in Fig. 5 below, blue stars indicate R/V Ride bore crossings, and pink stars indicate $\mathrm{R} / \mathrm{V}$ Ride front crossings. (b) As in (a), but extracted along the southern (offshore) transit.

for gravity currents (section 3c). The detached front also has a jagged shape, more notable in Fig. 3, which is likely related to southward-propagating alongfront instabilities (section 4c). Figure 2 also shows that a similar feature appears during the previous nonlinear wave packet arrival approximately $6 \mathrm{~h}$ earlier ( $\sim 0200 \mathrm{UTC})$; it is not analyzed here.

\section{b. Anatomy of a front}

The subsurface structure of this sharp, surface intensified front and trailing turbulent filaments is shown in Fig. 4. This ship crossing (A in Fig. 2) was made shortly before the front detaches from the internal bore in the radar image. The data have been placed into a cross shelf coordinate system (rotated $11^{\circ}$ south of due east), centered at the peak horizontal temperature gradient. On the offshore side (left; negative crossfront distance values), the warm water exhibits a series of filamentous structures, while on the onshore (right) side, the near-surface water is of a more uniform temperature. Lateral temperature gradients (Fig. 4b) reveal this structure in more detail. At the front there is a sharp horizontal temperature gradient $\left(\sim 0.1^{\circ} \mathrm{C} \mathrm{m}^{-1}\right)$ throughout the $15-\mathrm{m}$ depth range pictured. The temperature gradient of this front observed by the $\mathrm{R} / \mathrm{V}$ Sproul bow chain (not shown) is of similar magnitude. The trailing filaments show up as bright features in the temperature gradient. Turbulence in the front and trailing filaments are visible through acoustic backscatter (Fig. 4c); here sound is likely directly scattering off the turbulent billows (e.g., Moum et al. 2003b). Average microstructure profiles of turbulent dissipation (Fig. 4d) ahead of (green) and within/trailing the front (blue) reveal a 10-fold increase in turbulence from 10- to 30-m depth.
Expanding our view to the entire water column (Fig. 5, leftmost column), the full-depth transects of temperature, velocity and turbulent dissipation rate from this first ship crossing demonstrate that the feature shown in Fig. 4 has elements of both a sharp front and an onshore propagating internal bore. The sharp surface front is coincident with a depression bore of the type discussed in detail by McSweeney et al. (2020a,b). In the depression, the thermocline (yellow to blue transition color in the temperature panel) descends from 12 to $29 \mathrm{~m}$ deep from about 200 to $-200 \mathrm{~m}$ (and $400 \mathrm{~m}$ in the offshore direction).

Cross-shore velocity shows surface convergence near the surface at the bore front, and divergences at depth, as is typical of bores in this region (McSweeney et al. 2020a). The alongshore flow has a sharp cross-shore gradient, yielding a very large vertical vorticity $\sim d v / d x$ of $\sim O(100) f$. The vertical vorticity is aligned with the surface front but extends through nearly the entire water column. An analysis (not shown) of the alongshore currents ahead of all the bores identified in McSweeney et al. (2020a) revealed no consistent patterns in the cross-shore gradient of the alongshore currents, and we note that the strong cross-shore gradient in these observations is neither "unique" nor "typical."

\section{c. Evolution of the detaching front}

The subsurface evolution of the front and the bore ahead of it can be seen in both a series of ship crossings and in multiple time series from several nearby moorings. Over the five ship-crossings shown in Fig. 5, the near-surface temperature anomaly both weakened and shoaled in depth range. The first crossing (A) has the deepest and strongest temperature anomaly and clearest 

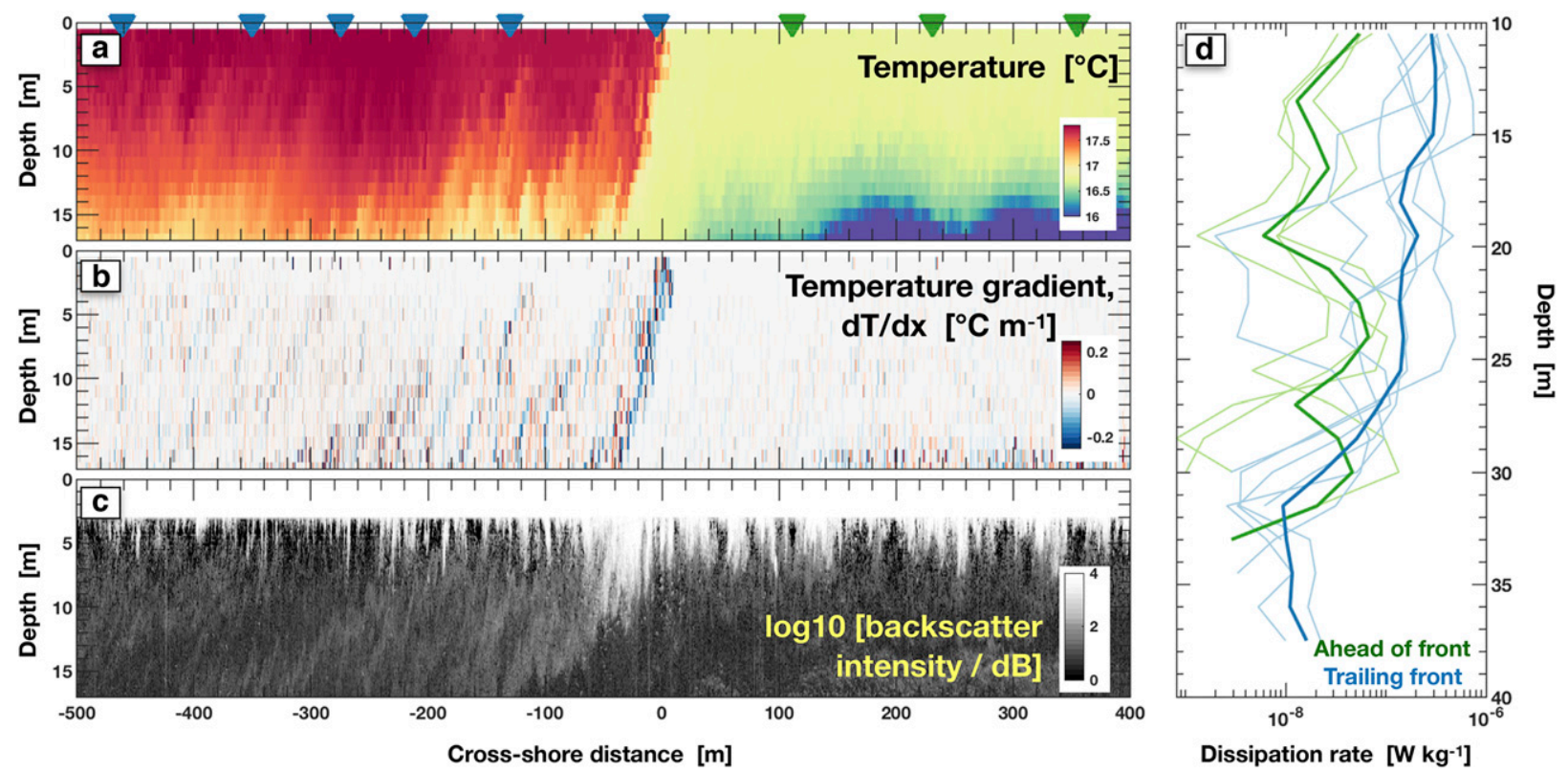

FIG. 4. Detailed front crossing as observed from the R/V Sally Ride. (a) Temperature as observed from the bow chain, placed in a reference frame centered at the front; positive cross-shore distance is toward the coast. (b) Along-track lateral gradients of bow chain temperature. (c) Acoustic backscatter intensity from the Biosonics echosounder. (d) Individual (thin) and average (thick) turbulent dissipation rate from three profiles ahead (onshore) of the front [green profiles, locations indicated with green triangles atop (a)], and six profiles at and trailing the front (blue).

cross-front convergence and took place when the front was still coincident with the onshore propagating bore in the radar image (Fig. 2). A strong cross-shore gradient in alongshore velocity (third row) is coincident with both the temperature front and gradients in cross-shore velocity. Turbulent kinetic energy dissipation rate and turbulent heat flux (bottom two panels) is enhanced at the front and behind it, visually roughly aligned with the vertical shear in cross-shore velocity. For the second crossing (B), the front is just starting to detach from the faster propagating bore as apparent in the radar image. In the subsurface view (Fig. 5, second column), both the deepening of the thermocline and the cross-front convergence of cross-front velocity have advanced several hundred meters ahead of the sharpest nearsurface temperature front (the $x$ axis is still centered at the surface temperature front). The cross-shore gradients in alongshore velocity stay most closely aligned with the front. Turbulence is still elevated at and trailing the front, in the region of high vertical shear.

By the third and fourth crossings (C and D), the radar image suggests the leading edge of the internal tide bore is approximately $1 \mathrm{~km}$ ahead of the front, out of the field of view of the ship survey. The front that is still visible by the ship (Fig. 5, third and fourth columns) is weaker and shallower. Cross-shore gradients in alongshore velocity (positive vertical vorticity) remains coincident with the front. In crossing $\mathrm{C}$ the turbulence takes on a strikingly different character, and is elevated at and beneath the front, throughout the entire water column; we briefly speculate about the source of this turbulence at the end of section $4 \mathrm{c}$. In the fourth crossing (D), a series of high-frequency waves can be seen catching up with the front, visible in isotherm displacement (black contour), alongshore and cross-shore velocity. The arrival of this internal wave packet can be seen in the radar image for crossing D. By the final crossing (E), the near-surface temperature front is no longer visible. Cross-shore velocities are weaker, and there are no strong cross-shore gradients in alongshore velocity. Elevated turbulence appears coincident with the arriving high-frequency wave packet.

Mooring records showcase a different perspective of the detaching front, and also provides a sense of spatial variability of its position relative to the bore (Fig. 6). Offshore, the outcropping isotherm that defines the front and plunging thermocline at the leading edge of the bore arrive at OC50 simultaneously. As they move onshore past OC40S and OC32S, the near-surface front increasingly lags behind the bore. While the bore is evident in all but the OC25NA mooring, the front is most apparent along the southern mooring line and completely disappears inshore of the $32-\mathrm{m}$ isobath. Note that as the bore moves onshore, the deepened thermocline becomes rarefied and appears flattened. The mooring array also gives a broader view of the full bore structure, including high-frequency internal waves that chase (and eventually catch as seen in the radar data) the front. The same high-frequency internal waves appear as bright bands in the radar data (Fig. 2) and are visible in transect D of the R/V Ride crossings (Fig. 5).

The cross-shore velocity data from the moorings echo what is seen from the ship, that is, strong surface convergence and deep divergence offshore that weakens as the bore moves onshore (Fig. 7). While offshore the surface convergence aligns with the surface front, at OC40S the convergence zone has moved somewhat ahead of the surface front. The cross-shore 


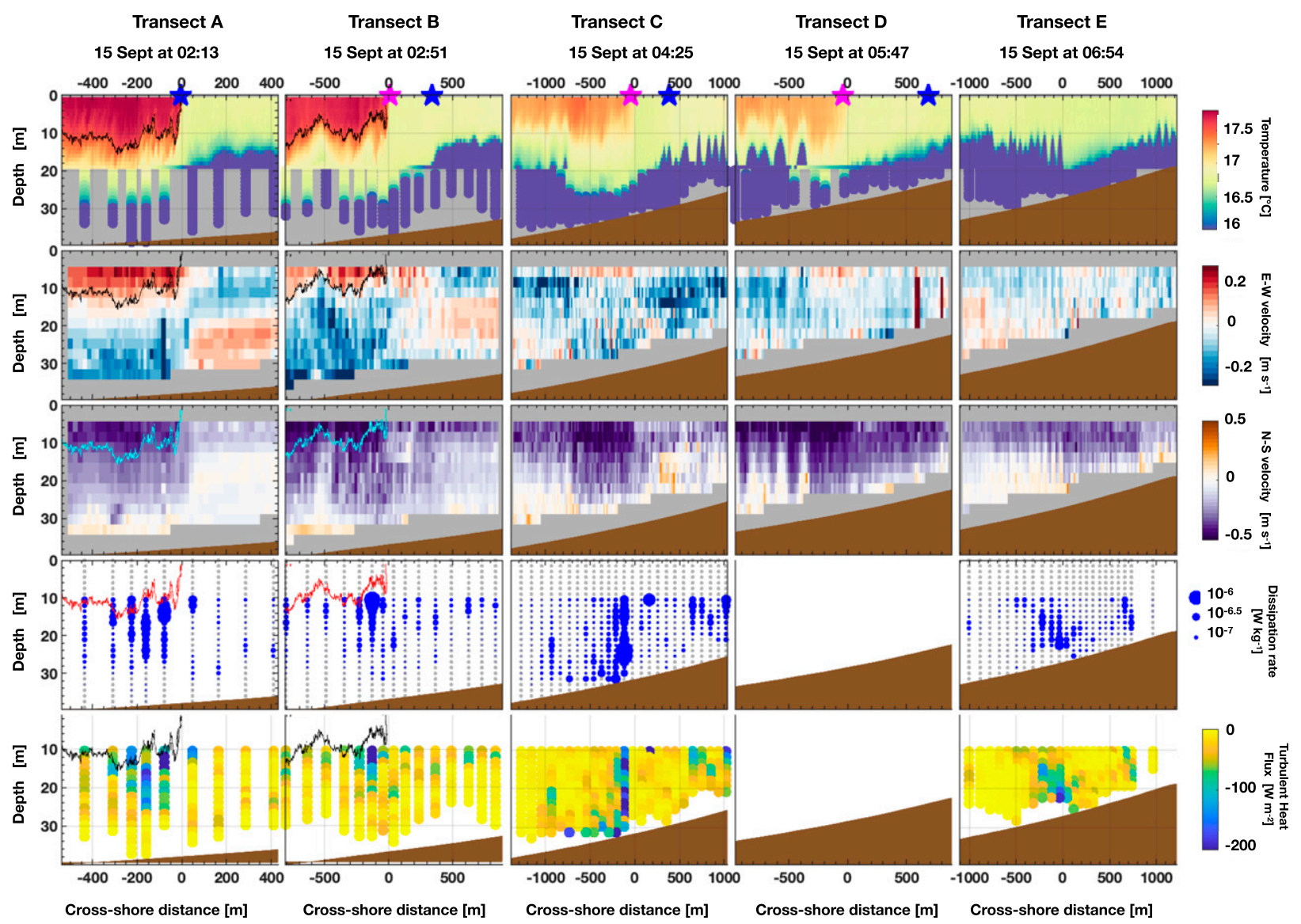

FIG. 5. Five transects on the R/V Sally Ride over a 4-h period on 15 Sep 2017. Plotted in each column, from top to bottom, are temperature from the bow chain $(0-20 \mathrm{~m})$ and towed VMP-CTD $(>20 \mathrm{~m})$, onshore velocity $u$ (rotated $11^{\circ}$ southward of due east), alongshore velocity $v$, turbulent dissipation rate $\left(\mathrm{W} \mathrm{kg}^{-1}\right)$ as measured from the VMP (not measured during section $\mathrm{D}$ ), and turbulent heat flux, where negative values indicate a downward flux of heat. The cross-shore coordinate system is rotated $11^{\circ}$ southward of due east, with each transect centered around the location of the front as visible in surface radar. The $17.1^{\circ} \mathrm{C}$ isotherm is contoured for transects $\mathrm{A}$ and $\mathrm{B}$. Above the top row, blue and magenta stars correspond to the bore and front crossing, respectively, as shown in Fig. 3.

gradient in alongshore velocity (vertical vorticity), however, appears to be more tightly bound to the surface front than to the bore. This is also evident in the shipboard data (Fig. 5). As with the temperature features of the front, the convergence and vorticity that are evident offshore have vanished by the $25-\mathrm{m}$ isobath.

The radar data allow the slowing speed of the detaching front seen in both ship-based and mooring observations to be quantified. The slopes of features in the space-time diagrams (Fig. 2) indicate their cross-shore propagation speed (note both total water depth and cross-front distance are marked on the ordinate axes). For the front of interest, the trajectories are manually identified and the estimated speeds along the northern and southern transits are shown as gray and black lines in Fig. 2c. It appears that the front is birthed from an internal bore traveling at $\sim 0.18 \mathrm{~m} \mathrm{~s}^{-1}$ and then falls behind the bore, sharply decreasing in speed to $\sim 0.05 \mathrm{~m} \mathrm{~s}^{-1}$ over a shoreward propagation distance of about $1.5 \mathrm{~km}$.

The first clue that this front is propagating as a gravity current comes from analysis of its speed. The associated expected gravity current speed, $C_{\mathrm{GC}} \approx\left(g^{\prime} H_{\text {Total }}\right)^{1 / 2} / 2$, is estimated at the locations of the R/V Ride front crossings indicated by open cyan and purple circles. To compute $g^{\prime}$, we use the lateral density difference across the front using the temperature and salinity measured at roughly 2-m depth on the R/V Ride bow chain. These theoretical speeds are indicated by cyan and purple circles in Fig. $2 \mathrm{c}$ and are connected with a dashed line. The front is initially faster than gravity current theory would suggest but slows down to a speed that is comparable to theory by the time it becomes barely visible in the radar image. Note that this slowing to the gravity current speed is an interesting contrast to the front turned gravity current observed by Warner et al. (2018), which speeds up as it transitions from balanced to unbalanced, propagating dynamics.

\section{Discussion}

The observations described above illustrate the life cycle of a sharp, surface-intensified front birthed from an internal tidal 

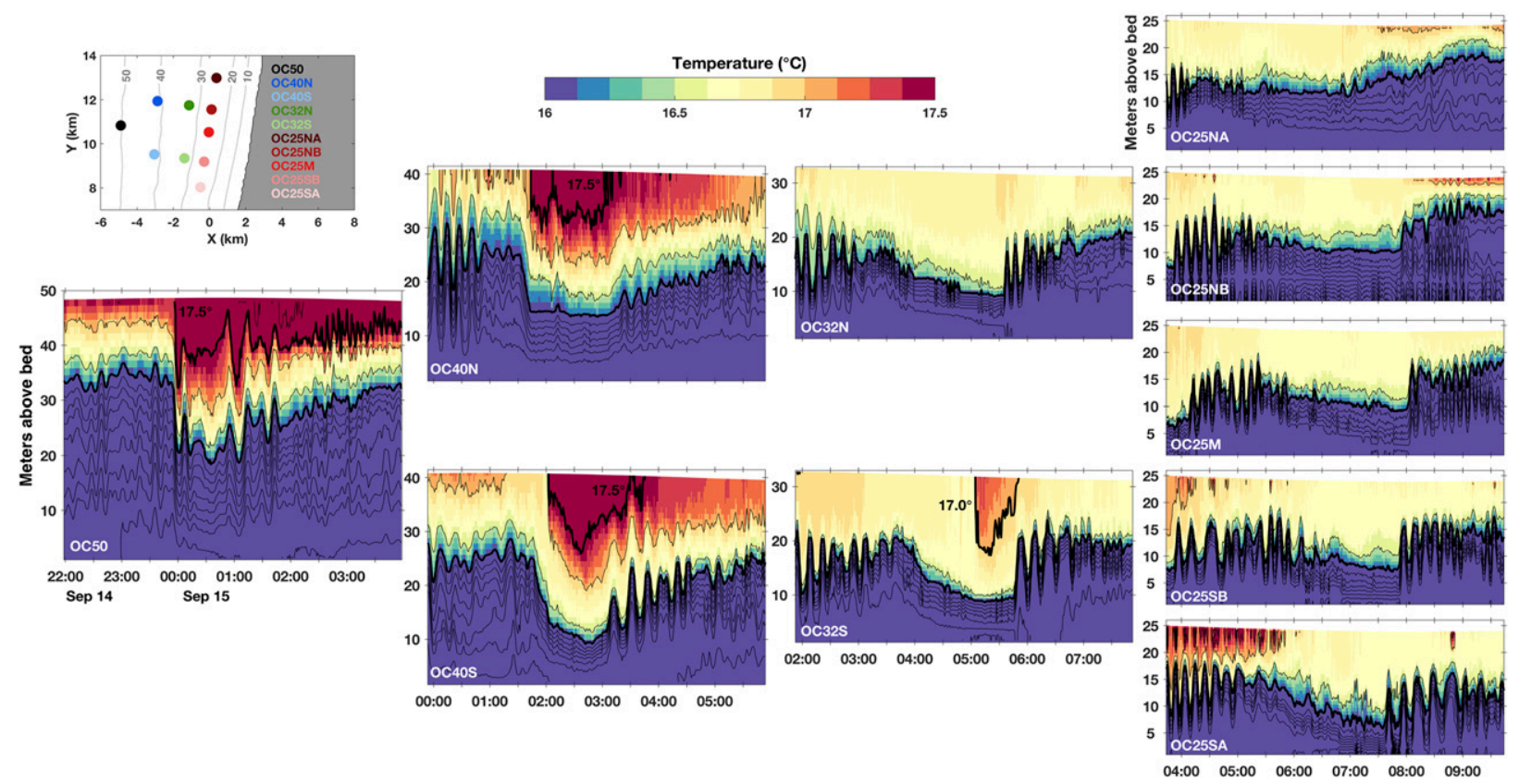

FIG. 6. Temperature data from the Oceano mooring array; $0.5^{\circ}$ intervals are contoured in black, with the thick contour indicating the frontal feature on which this paper focuses. The thick contour's value is indicated in each panel. The mooring sites span water depths of 50$25 \mathrm{~m}$. The insert at top left shows a labeled map with bathymetry contoured at $10-\mathrm{m}$ intervals. Numbers in mooring names indicate the water depth at that site.

bore. The front is initially coincident with the bore, but is then left behind, propagating onshore as a gravity current, more slowly than both the bore and the high-frequency internal waves (e.g., Fig. 2). It has an evolving structure, visible both subsurface (Figs. 5-7) and from above (Figs. 1-3), schematically portrayed in Fig. 8. After separation from the bore, the front is visible for about $4 \mathrm{~h}$ and $2 \mathrm{~km}$ of propagation distance and then disappears from view. Here we discuss these
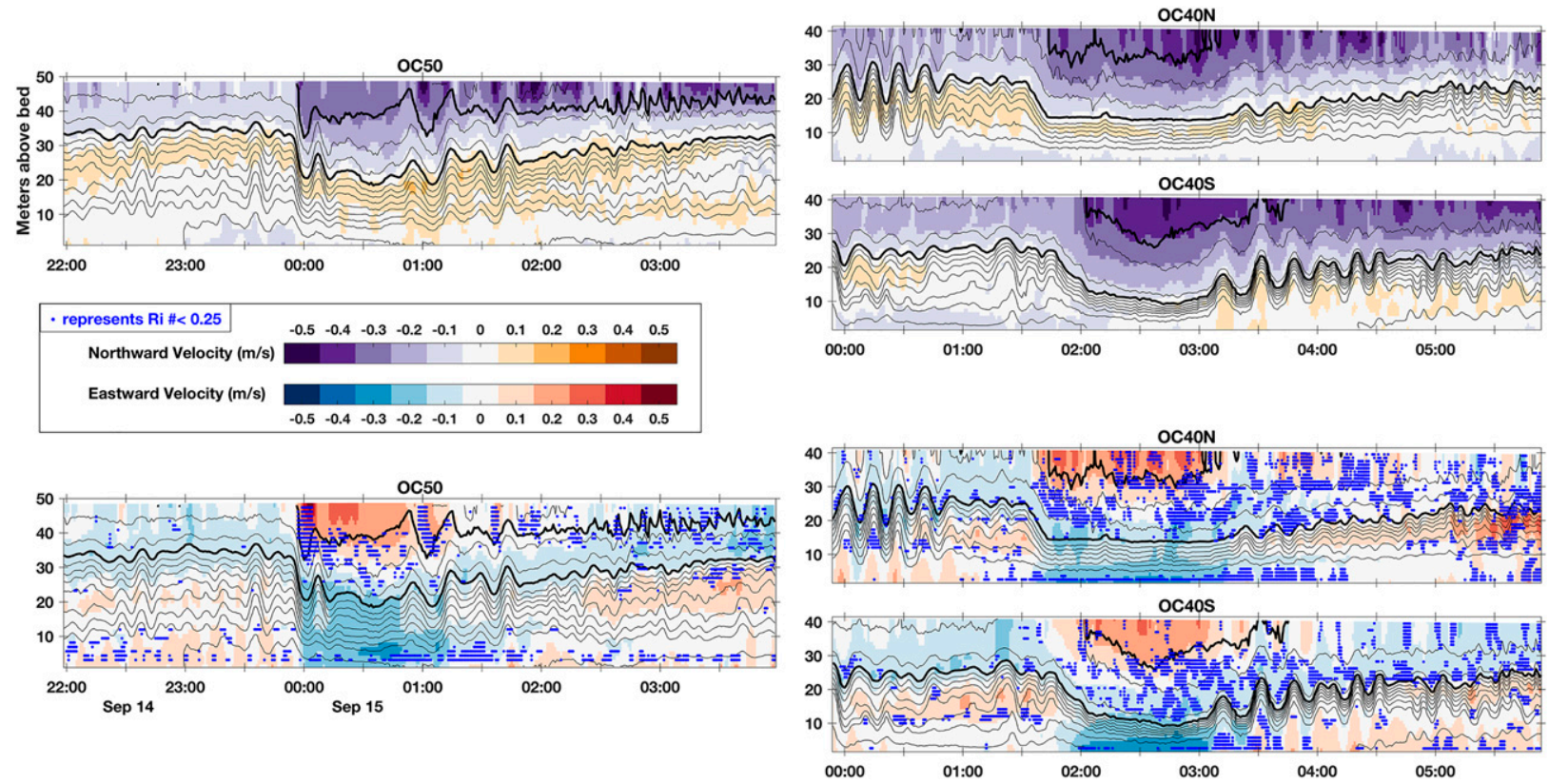

FIG. 7. (top) Alongshore and (bottom) cross-shore velocities from moorings OC50, OC40N, and OC40S (6) As in Fig. 5, the cross-shore coordinate system is rotated $11^{\circ}$ southward of due east, and velocities are positive onshore and northward. In bottom panels, the blue dots indicate depths and times at which the Richardson ( $\mathrm{Ri}$ ) number is less than 0.25 . 


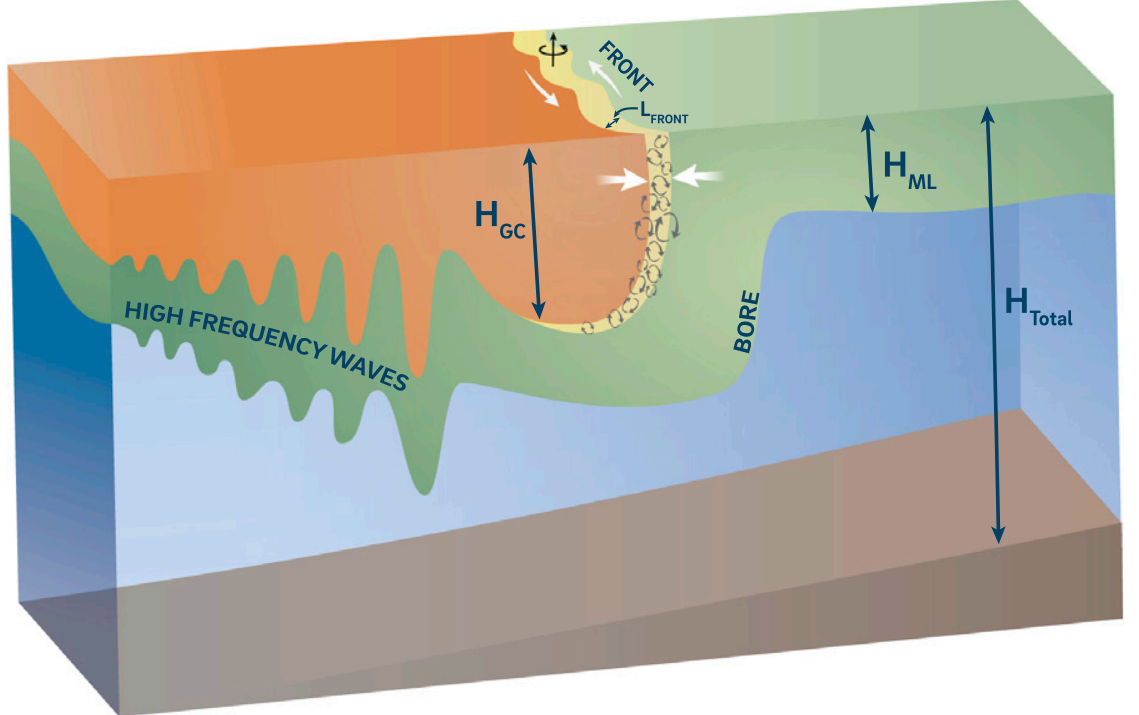

FIG. 8. Illustration of an interaction between a tidal bore and trailing surface front. White arrows indicate cross and alongshore velocities. Recirculating gray arrows indicate turbulence at the front. Relevant length scales are width of the front $\left(L_{\text {Front }}\right)$, depth of the gravity current $\left(H_{\mathrm{GC}}\right)$, depth of the mixed layer $\left(H_{\mathrm{ML}}\right)$, and total depth $\left(H_{\text {Total }}\right)$.

observations in light of potential mechanisms for front generation, evolution, and destruction.

\section{a. Generation and evolution of the front}

The generation and evolution of shoaling internal tidal bores are active research topics (Lamb 1994; Holloway et al. 1997; Scotti et al. 2007), and, to our knowledge, the data presented here represent the first observational evidence of a shoaling internal bore generating a gravity current front. The instrumentation was concentrated on the inner shelf, so the formation of the internal tidal bore farther offshore was not captured; we only observe how the internal bore evolves across the inner shelf. One question that emerges is how this particular bore's evolution gives rise to the formation of the front and why the front detaches and subsequently propagates so slowly relative to the bore's speed. Given the range of shoaling bore dynamics that have previously been described from the 2-month mooring dataset (McSweeney et al. 2020a,b), we suggest that the stratification and current shear ahead of the bore (i.e., the upstream waveguide) are relevant to both the bore's cross-shore evolution and to the evolution of the high-frequency waves that trail behind the bore. We observe that this bore encounters a pycnocline that is about middepth in the water column, consistent with observations of $\alpha$, the quadratic nonlinearity coefficient in the Kortewegde Vries equation, being near zero (McSweeney et al. 2020a). It is likely that the bore also transits through the critical depth, where $\alpha$ changes sign from positive to negative (Helfrich et al. 1984; Vlasenko and Stashchuk 2007; Shroyer et al. 2009), which would entail the high-frequency internal waves switching polarity from depression to elevation waves. These waveguide conditions do not appear to necessitate the formation of a secondary front, but we do note that other gravity current fronts were observed during similar waveguide conditions throughout the record (such as that observed behind the earlier internal tide in Fig. 2 at 26-m depth at 0200 UTC).

The bore and gravity current are first observed at OC50, where they are still coincident, (Figs. 6 and 7, left-most panel in each). Near the 40-m isobath, the two features have begun to separate. By this we mean that the thermocline depression (bore) is beginning to leave the near vertical outcropping isopycnals (gravity current front) behind. With this sort of separation, the ensuing flattened wave that connects the two separated features is often referred to as a rarefaction (e.g., Melville and Helfrich 1987). McSweeney et al. (2020a) demonstrate that these rarefactions occur in this region when the pycnocline depth exceeds one-half of the total water depth, a condition not often observed this far offshore.

The phenomenology and dynamical properties of nonlinear internal waves and gravity currents have been linked through a series of previous analyses (e.g., Benjamin 1968; Rottman and Simpson 1989; Lamb and Wilkie 2004; Nash and Moum 2005; White and Helfrich 2008; Kilcher and Nash 2010; White and Helfrich 2012). Most previous work involves causality in the opposite direction from what was observed here, i.e., internal waves spawned from a gravity current propagating into stratified fluid. For the present analysis, the crucial insight is to recognize the equivalence between (i) a buoyancy-driven gravity current with large enough amplitude to water depth ratio to approach the critical Froude number and (ii) a particular limiting case sometimes experienced by shoaling internal bores. In this limiting bore case, the increasing amplitude does not lead to wave breaking but instead a horizontally elongated "flat-bottomed" bore, in which the growing horizontal extent conserves energy and the 


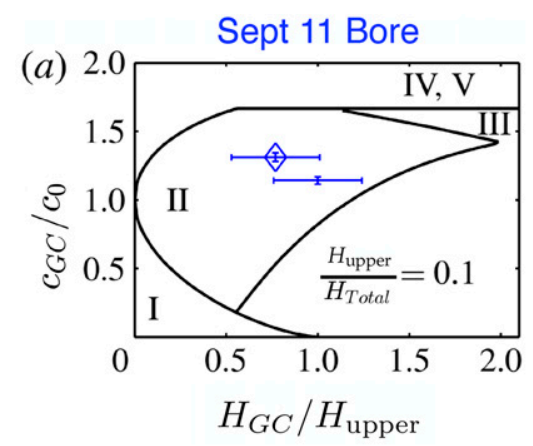

(d)

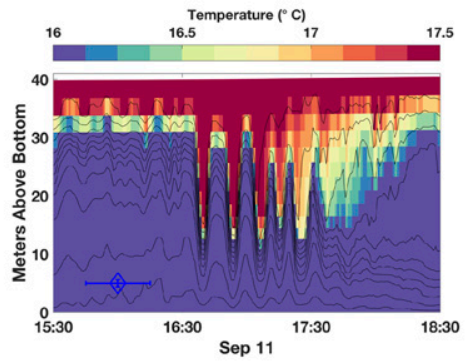

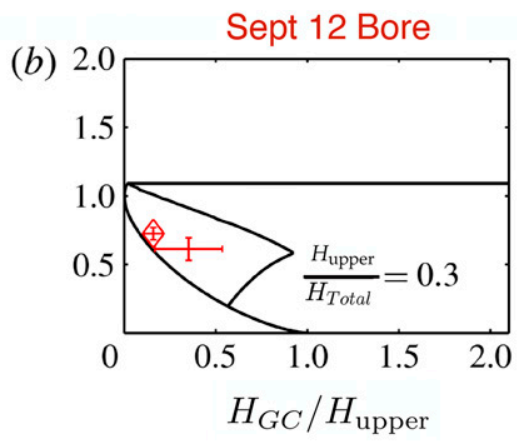

(e)

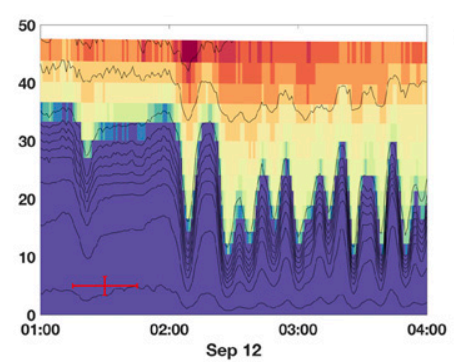

Sept 15 Bore

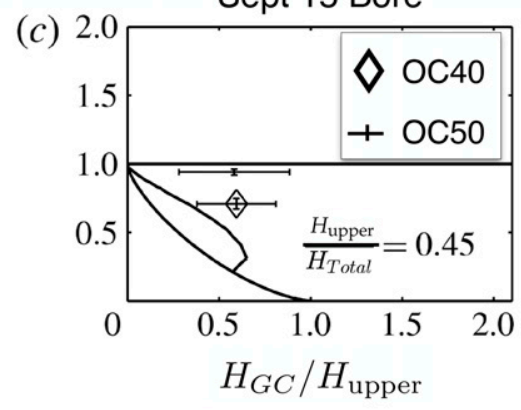

$(f)$

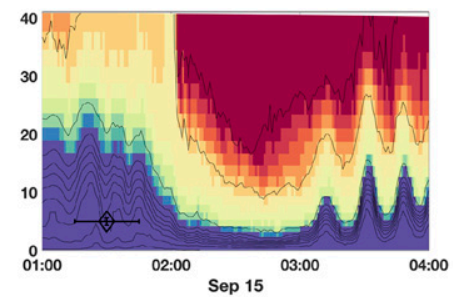

FIG. 9. Modified Fig. 4 from White and Helfrich (2012), to include the bore under primary consideration here (15 Sep bore), and two other examples that exhibit different behavior. (a)-(c) Regime diagrams from White and Helfrich (2012) for different values of $H_{\text {upper }} / H_{\text {Total }}$, where $H_{\text {upper }}$ is the height of the upper layer, roughly the distance from the surface to the main thermocline, and $H_{\text {Total }}$ is the total water depth. The $x$ axis is the ratio of the gravity current height $H_{\mathrm{GC}}$ to the upper layer, and the $y$ axis is the ratio of the gravity current speed to the mode-1 linear phase speed for this stratification. Three different bores at two mooring locations are shown in their respective parts of parameter space, with error bars that indicate 1 standard deviation. Note that the values of $H_{\text {upper }} / H_{\text {Total }}$ for the 11 Sep bore at OC40 and OC50 are 0.14 and 0.19, respectively. (d)-(f) Plots of bore temperature from the moorings for three of the six examples as indicated by the symbols in the lower-left corner. Compare (d) and (e) with Fig. 6 and (f) with Fig. 7, both from White and Helfrich (2012).

upstream undisturbed stratification is linked to the adjusted downstream isopycnal locations through a dissipation-less jump (White and Helfrich 2008). This latter situation is often dubbed the conjugate state, in light of the conjoined but complementary upstream and downstream thermocline conditions (Benjamin 1966). In idealized conditions, this conjugate state bore/gravity current occupies half the water depth, and is the fastest internal wave allowed.

Observations from the farthest-offshore moorings are consistent with this state, with a bore-like depression making up half the water column (Figs. 6 and 7, left-most panels in each). At this point it is reasonable to interpret the situation as a conjugate style bore, or a gravity current; the equivalency described above argues that either or both are appropriate, both solutions can be considered superimposed at this time. Here we argue that as this feature continues to shoal into shallower water, that equivalency allows it to separate into a propagating rarefied internal wave and a slower moving surface-intensified gravity current.

The nature of that subsequent separation is well described by the theory and simulations of White and Helfrich (2012). They approach the situation from a different starting point, that of a gravity current propagating into a stratified fluid. An observational example of getting to the equivalence point by starting with a gravity current is shown in Solodoch et al. (2020). For two-dimensional gravity currents, Benjamin (1968) used the Bernoulli equation to show that the depth of the gravity current $H_{\mathrm{GC}}$ will not exceed one-half of the total depth $H_{\text {Total }}$, if it is energy conserving. Furthermore, he showed that for $0.2<H_{\mathrm{GC}} / H_{\text {Total }}<0.5$ the speed of the gravity current front is relatively constant, $C_{\mathrm{GC}} \approx\left(g^{\prime} H_{\text {Total }}\right)^{1 / 2} / 2$.

Figure 9 is a modified version of Fig. 4 from White and Helfrich (2012), showing five regimes that they delineate for gravity current evolution, as a function of gravity current height normalized by the distance from ocean surface to the thermocline ( $x$ axis) and gravity current speed relative to the mode-1 linear wave speed ( $y$ axis). The conceptually simplest cases that they consider are either purely subcritical (type I) or purely supercritical (types IV and V), the latter happening for $c_{\mathrm{GC}} / c_{0}>1$ where $c_{\mathrm{GC}}$ is the gravity current speed and $c_{0}$ is the linear mode- 1 internal wave speed in the undisturbed upstream stratification. The more interesting situations are transcritical regimes II and III, in which different types of upstream propagating features are allowed, generated by quasi-resonant interaction between gravity current speed and linear wave speeds, using both the pure undisturbed upstream stratification and that influenced by the gravity current isopycnal deflections. In regime II, undular bores or solitary waves propagate ahead of a gravity current. Regime II conditions are encountered several days earlier in our observations, with commensurate observations of leading solitons (Figs. 9a,b,d,e).

The boundary between transcritical regimes II and III occurs at the conjugate state described above. Past this point, 
instead of a train of waves, theory predicts a monotonic upstream bore connected to the gravity current front by an expanding rarefaction. Though the situation depicted in our observations starts with a tidal bore and not a gravity current, we posit that at the $50-\mathrm{m}$ isobath the system is on that dividing line between regimes II and III and can be thought of equivalently as either a conjugate state bore or a gravity current. As the feature continues to shoal, it takes a larger percentage of the water column, pushing the state to the right in the phase diagram (Fig. 9c; into regime III). In this regime a single rarefied wave propagates ahead, leaving a gravity current with associated leading front behind. The evolution of this process is evident in Fig. 6, particularly along the southern mooring line. As the bore shoals between the 50- and 40-m isobaths, the thermocline depression deepens and now occupies more than half of the water depth at OC40S. At this point the gravity current and bore become decoupled. Farther onshore, mooring (Fig. 6; OC32S) and shipboard observations (Fig. 5; transect C) show a thermocline depression moving ahead of a sharp surface front. The front continues to propagate onshore but more slowly; front propagation speeds observed in the radar near the 32-m isobath (Fig. 2c) match those predicted for a gravity current by Benjamin (1968).

\section{b. Relationship to the broader category of frontogenesis}

This example of front formation through evolution of, and subsequently detachment from, a nonlinear tidal bore is to our knowledge a new (observational) contribution to the increasingly diverse array of frontogenetic processes in the ocean (Mahadevan and Tandon 2006; McWilliams 2021). The classic view of frontogenesis in the ocean (Hoskins and Bretherton 1972) is instigated by a sharpening of preexisting lateral density gradients through confluence of mesoscale currents. As a front sharpens through confluence, frontal sharpening is accelerated through a secondary circulation, which enhances the local convergence rate to create a runaway affect.

More recent work by Barkan et al. (2019) highlights that an analogous runaway frontogenesis process can be produced from a wide variety of initial forcing conditions. Once it gets going, there is often an interplay between growing convergence at the front, vertical velocity, growing vorticity, and sharpening buoyancy gradients. Crucially, they argue that once the lateral convergence rate becomes strong (relative to the inertial frequency), the processes play out in a similar manner regardless of the initial instigation; the system has "forgotten" how it got started on the route to frontogenesis (e.g., Wang et al. 2021). Though the instigating convergence here comes from an internal tide instead of a mesoscale process, the evolution of this front bears some similarity to the situation described in Barkan et al. (2019). Both the observed frontal convergence rate and positive (cyclonic) vorticity at the front (onshore gradient of alongshore velocity) are of order $\sim 30-50 f$ at this lateral resolution. We suspect that similar runaway frontogenesis effects may act to sharpen the front observed here. Finally, for steep enough fronts initially created through any mechanism, the dominant momentum balance may shift from a roughly balanced one (through inviscid or turbulent thermal wind) to that of a propagating gravity current (Warner et al. 2018; Pham and Sarkar 2018).

\section{c. Destruction}

The sections above discuss potential processes creating the formation and sharpening of the front shown here, which propagates shoreward as a gravity current. The observations also show the front to diminish in both strength and vertical extent over roughly $4 \mathrm{~h}$, eventually disappearing from view in the remote and subsurface data. Here we discuss several processes that may contribute to the front's destruction. While each of these mechanisms likely plays a role in the frontal evolution, southward advection of the entire feature (visible in the movie in the online supplemental material) may dominate the disappearance of this feature from the shipboard and moored data at this latitude.

The first possibility is that some of the heat may be turbulently mixed downward. Microstructure profiles show that turbulence is elevated on average on the warm side relative to the cool side of the front (Fig. 4, right). Comparison of turbulence from multiple ship passes (Fig. 5, fourth row) reveals a complex structure that is often intensified right at the front (crossings 1 and 2) but sometimes has more of a full depth structure (crossing 3). Zooming in on the first crossing in detail, the rich structure in both lateral temperature gradients (Fig. 4b) and acoustic backscatter (Fig. 4c) are consistent with a series of turbulent billows trailing the front. The billows are visually suggestive of a shear instability process (Smyth and Moum 2012; Geyer et al. 2010). The mooring records confirm that a Richardson number criterion for shear instability is frequently met during and following front passage (Fig. 7), especially along the interface of the front.

Downward turbulent heat fluxes are shown in the bottom row of Fig. 5. Downward turbulent heat fluxes at the leading edge of the front and beneath the warmest water are of order $\sim 100-300 \mathrm{~W} \mathrm{~m}^{-2}$. Upward heat loss to the atmosphere during this time was $\approx 90 \mathrm{Wm}^{-2}$, as calculated from shipboard meteorological sensors using standard bulk formula (Fairall et al. 2003). These heat fluxes can be compared with the observed loss of heat on the warm side of the front throughout the night. Figure 10 shows the decrease in the temperature jump moving from the cooler (onshore) to the warmer (offshore) side of the front, from three different ships. If this pattern were to be caused by downward turbulent heat fluxes from the warm side of the front only, the observed level of cooling would require approximately $\sim 4000 \mathrm{~W} \mathrm{~m}^{-2}$ of heat loss, assuming a 15-m warm-layer depth (Fig. 10, right). Although the observed turbulent heat fluxes are substantial, they are not sufficient to fully explain the observed rapid loss in heat.

In addition to turbulent mixing, there is also an indication in the radar image sequences that the front develops lateral shear instabilities as it propagates toward shore. For example, Fig. 11 shows three radar snapshots (Figs. 11a-c) over the span of $3.5 \mathrm{~h}$, each synchronous with a R/V Ride front crossing. In Fig. 11a, the front is observed in $\sim 36-\mathrm{m}$ water depth, with some weakly visible alongfront structure. In Fig. 11b, the 

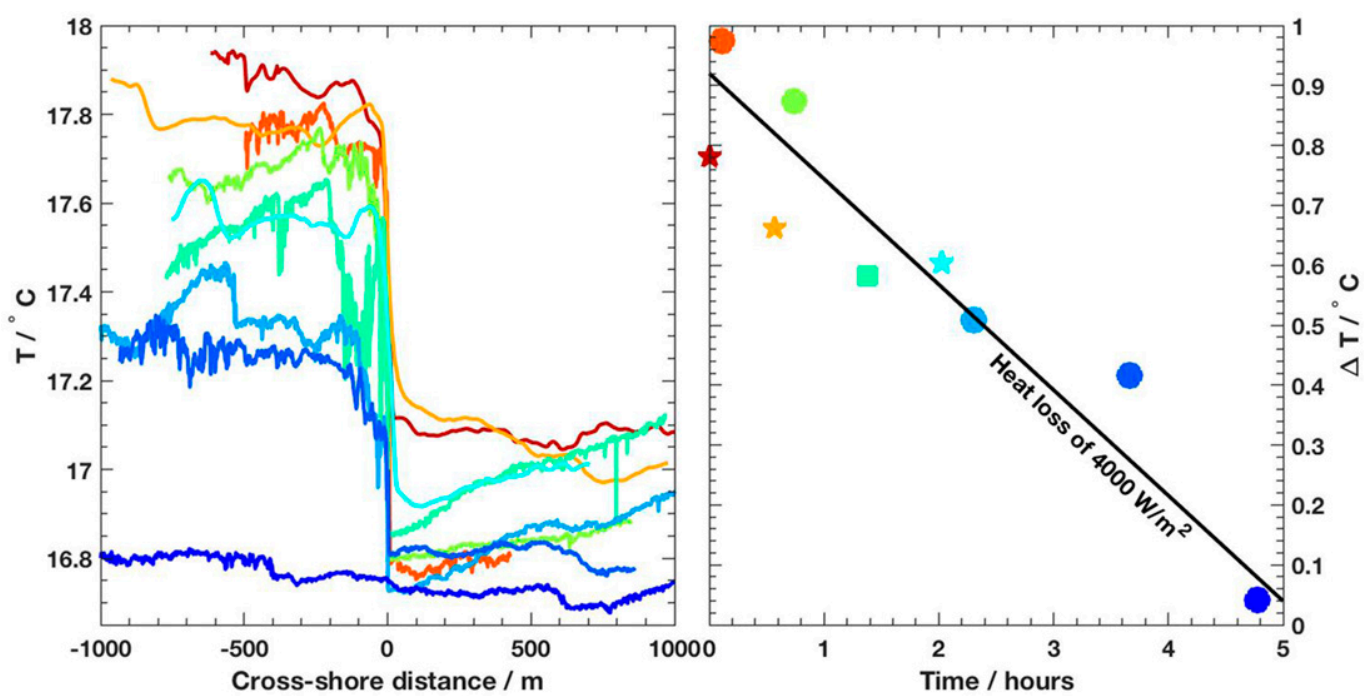

FIG. 10. Frontal temperature destruction over a 4.5-h period as observed from the R/Vs Sally Ride, Oceanus, and Sproul underway instrumentation. (left) Succession of near-surface cross-front temperature measurements colored by time of ship crossing (from red to blue), from R/V Oceanus (smoother lines) and R/V Ride (rougher lines) from the shipboard flowthrough and top bow chain sensor, respectively. As with Fig. 5, the $x$ axis is cross-shore distance, centered around the front. (right) Difference between the average temperature within $200 \mathrm{~m}$ offshore of the front and $200 \mathrm{~m}$ onshore of the front, over time. Here the $x$ axis is time in hours from the initial survey, conveying the same information as color; the color matches the curves in the left panel. The black line indicates the hypothetical temperature if the offshore side only were cooled by a heat loss of $4000 \mathrm{~W} \mathrm{~m}^{-2}$ over a $15-\mathrm{m}$ surface warm layer. Circles, a square, and stars indicate observations from the R/Vs Ride, Sproul, and Oceanus, respectively.

front is observed 35 min later but the water depth is only slightly less, $\sim 35 \mathrm{~m}$, with more noticeable alongshore wavelike structure. As the front continues to propagate to shore, this alongshore structure appears to lengthen as seen in Fig. 11c at the time of R/V Ride front crossing D in $\sim 26-\mathrm{m}$ water depth.

Lateral shear instabilities on gravity currents are not well understood. White and Helfrich (2013) numerically simulated shear instabilities due to across-front shear in the alongfront velocities of an idealized gravity current system. They associate the existence of these instabilities with $O(1)$ values of a nondimensional parameter $\gamma$ that is the ratio of the representative time scales for growth of horizontal shear instability $\tau_{s}$ versus that of gravitational adjustment $\tau_{\mathrm{gc}}$. This ratio is defined as

$$
\gamma=\frac{\tau_{s}}{\tau_{\mathrm{gc}}}=\frac{10 l_{v}}{|\Delta V|} \frac{\left(g^{\prime} H_{\mathrm{Total}}\right)^{1 / 2}}{2 H_{\mathrm{Total}}}=\frac{10 l_{v}}{|\Delta V|} \frac{C_{\mathrm{GC}}}{H_{\mathrm{Total}}},
$$

where $H_{\text {Total }}$ represents the total water depth, $l_{v}$ is the halfwidth of the horizontal shear layer, and $\Delta V$ is the difference in alongfront velocity across the front. The propagation speed of the gravity current $C_{\mathrm{GC}}$ is taken here as $\left(g^{\prime} H_{\text {Total }}\right)^{1 / 2} / 2$. Values of $\gamma \leq O(1)$ support the existence of shear instabilities, while larger values would suggest that gravitational adjustment occurs at much faster time scales.

Each of the terms in $\gamma$ can be roughly estimated at the different cross-shore locations and depths corresponding to the R/V Ride crossings of the front and are listed in Table 1.
The across-front change in velocity $\Delta V$ is taken as the difference in velocities averaged from 100 to $400 \mathrm{~m}$ on either side of the front. These velocities were measured from the R/V Ride near-surface side-mounted ADCP at 5.7-m depth. A 20 -s moving average is applied to the $1-\mathrm{Hz}$ measurements to filter out surface wave orbital velocities. This 20 -s filtering corresponds to $20-\mathrm{m}$ filtering in space ( $1 \mathrm{~m} \mathrm{~s}^{-1}$ ship velocity), which limits the possibility of estimating the shear layer halfwidth $l_{v}$ from the velocity data. In essence, because of the necessary averaging, an $l_{v}$ of less than $20 \mathrm{~m}$ cannot be resolved by the side-mounted ADCP. Thus, $l_{v}$ is instead estimated using the sharp change in $g^{\prime}$ (equivalently temperature). For this, $l_{v}$ is the distance at which $g^{\prime}$ reaches $50 \%$ of the average $g^{\prime}$ values between 20 and $60 \mathrm{~m}$ on either side of the front. This method yields $l_{v}$ values of $2-10 \mathrm{~m}$, consistent with that observed in Fig. 4.

The final parameter needed to compute $\gamma$ is the gravity current speed $C_{\mathrm{GC}}$, which we take directly from the radar space-time plots at the locations of $\mathrm{R} / \mathrm{V}$ Ride frontal crossings shown in Fig. 2 and discussed in section $3 \mathrm{~b}$. Estimated values of $\gamma$ reported in Table 1 are clearly $O(1)$. This indicates the potential for horizontal shear instability in this gravity current. It is also evident that $\gamma$ decreases as the crossings get closer to shore, which only further supports the potential for shear instability as the front propagates onshore.

Linear shear instability theory (Michalke 1964) would suggest that the most unstable wavenumber is $k \approx 0.45 / l_{v}$. According to this, the $l_{v}$ values estimated from $g^{\prime}$ would yield 

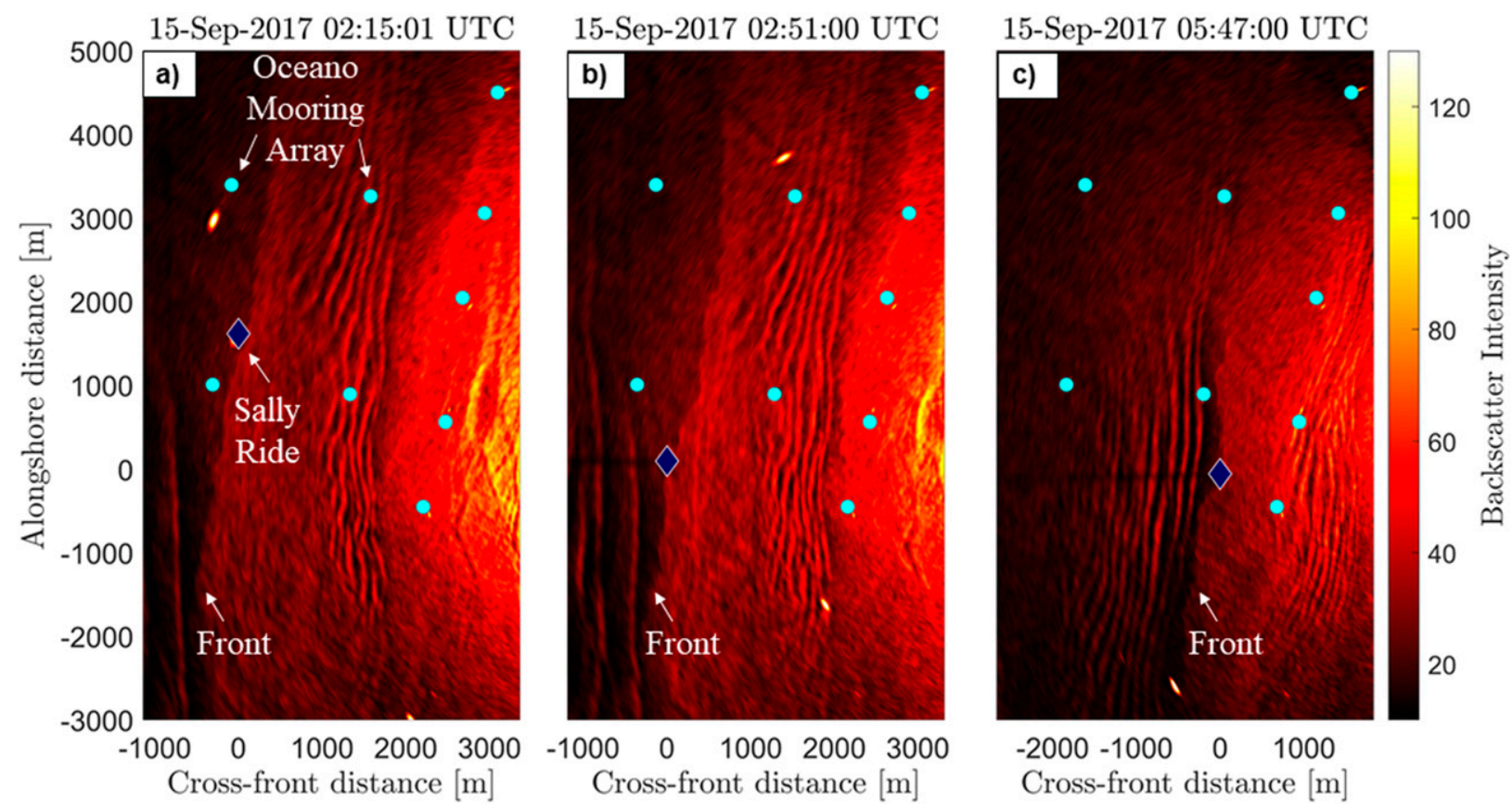

FIG. 11. Snapshots of radar imagery synchronous with the R/V Sally Ride frontal crossings (a) A, (b) B, and (c) D. The abscissa in each pane indicates distance from the R/V Ride frontal crossing. The ordinate in each panel indicates alongshore distance, where the radar is the origin.

wavelengths of 30-140 m. However, manual measurements of the instability wavelengths in the radar imagery (Fig. 11) indicate observed wavelengths of $550-700 \mathrm{~m}$, larger than the linear theory would suggest. Note that, at the offshore distance of the instabilities, the azimuthal resolution of the radar is approximately $70 \mathrm{~m}$, thus limiting the lower bound of observable wavelengths. Additionally, values of $l_{v}$ determined via momentum may not be equal to that via temperature, as we have assumed here. It is possible that nonlinearity contributes to the longer wavelength of the observed instabilities as compared with linear theory. Baroclinic instability can be ruled out as the cause by using the scales for buoyancy frequency, water depth, and Coriolis parameter at the study site in an Eady-type model (Chen et al. 2020). From these, we calculate a length scale for the fastest growing baroclinic instability as $O(10 \mathrm{~km})$, which is an order-of-magnitude longer than the observed instabilities.

This sort of lateral shear instability may conspire with vertical instabilities to enhance turbulent mixing in ways not fully captured by these measurements, nor well understood. It is, however, intriguing to note that near the time lateral instabilities are observed developing in the radar, turbulence in transect $\mathrm{C}$ is elevated throughout the entire water column (Fig. 5). The lateral shear instability is drawing energy from alongshore currents, which also extend throughout nearly the entire water column.

Some part of the observed evolution between ship transects observed in Fig. 5 may reflect southward advection of a warm filament with finite alongshore extent. In an animated version of the radar images (included in the online supplemental material) the warmest water appears to be propagating southward, out of the field of view of these measurements. This alongshore temperature gradient and southward advection likely explains the order of magnitude difference.

\section{Conclusions}

Here we have described the life cycle of a submesoscale front that decouples from a shoaling internal bore, through the lenses of shipboard, in situ, and remote measurements.

TABLE 1. Estimated $\gamma$ values and parameters used for calculation. Each of the four $\gamma$ values corresponds in space and time to a front crossing (A-D) by the R/V Sally Ride.

\begin{tabular}{ccccc}
\hline \hline R/V Sally Ride transit & $H_{\text {Total }}$ & $\Delta V$ & $l_{v}$ & $C_{\mathrm{GC}}$ \\
\hline A & $36.6 \mathrm{~m}$ & $0.23 \mathrm{~m} \mathrm{~s}^{-1}$ & $10.2 \mathrm{~m}$ & $0.171 \mathrm{~m} \mathrm{~s}^{-1}$ \\
B & $35.1 \mathrm{~m}$ & $0.13 \mathrm{~m} \mathrm{~s}^{-1}$ & $3 \mathrm{~m}$ & $0.166 \mathrm{~m} \mathrm{~s}^{-1}$ \\
C & $30.3 \mathrm{~m}$ & $0.23 \mathrm{~m} \mathrm{~s}^{-1}$ & $5 \mathrm{~m}$ & $0.088 \mathrm{~m} \mathrm{~s}^{-1}$ \\
D & $26.5 \mathrm{~m}$ & $0.26 \mathrm{~m} \mathrm{~s}^{-1}$ & $2.6 \mathrm{~m}$ & $0.072 \mathrm{~m} \mathrm{~s}^{-1}$ \\
\hline
\end{tabular}


As the bore propagates onshore, it steepens and grows to occupy more than half the water column. Its amplitude and speed put it in a near-critical state, in comparison with the internal wave phase speed appropriate for the upstream water into which it is propagating. In this state it can be described as either a particular solution to the nonlinear internal wave equation, known as a conjugate state wave, or equivalently as a critical gravity current; those two phenomena are in some sense thus superimposed (White and Helfrich 2012). As the feature moves farther onshore, continued shoaling breaks the symmetry, and the feature decomposes into a faster-moving rarefied wave and a trailing gravity current front. The type of rarefaction behavior of the internal bore seen here is neither common nor rare, but rather one of at least a handful of personalities these shoaling bores may assume depending on their amplitude and the stratification ahead of them. In fact, the bore immediately preceding the one discussed here displayed the same rarefaction behavior. Given the generality of the conditions, this type of relationship between internal bores and gravity current fronts may be not uncommon in other places where internal waves shoal.

After calving from the bore, the gravity current and associated sharp front are encompassed by turbulence that grows from both the lateral and vertical shear. At the frontal interface and in the wake of the front, the Richardson number dips below 0.25 , implying the potential for vertical shear instability. The measured dissipation rate at and below the front exceeds that of the surroundings by orders of magnitude, with downward turbulent heat fluxes of $200-300 \mathrm{~W} \mathrm{~m}^{-2}$. The cross-shore shear of the alongshore velocity at the front is also very high (Ro 40), suggesting that lateral shear instability plays a role in modulating the gravity current front. To test this we compared the lateral shear instability time scale with the gravity current propagation time scale as defined by White and Helfrich (2013). As the gravity current slows to its theoretical speed $\left[C_{\mathrm{GC}}=\left(g^{\prime} H_{\text {Total }}\right)^{1 / 2} / 2\right]$, lateral shear instabilities likely contribute to its destruction. Southward advection of the entire feature outside of our observational region prevents closure of an energy or heat budget.

While there remain many unanswered issues, we choose to highlight three that we find to be particularly intriguing. First, sharp cross-shore gradients in strong alongshore flow create a large vertical vorticity. The southward flow is initially coincident with the steepening tidal bore. It may reflect a combination of wave origin and initial cross-shore orientation, the influence of rotation, or preexisting wind-driven alongshore currents. An analysis of the full range of bores described in McSweeney et al. (2020a,b) (not shown here) reveals no consistent patterns for the direction or strength of alongshore currents associated with onshore-propagating bores. Interestingly, when the front separates and lags behind the bore propagating onshore, the sharpest vertical vorticity stays locked with the front, perhaps reflecting the types of frontogenesis processes described by Barkan et al. (2019). Second, with a wide range of scales linking the linear internal tide, nonlinear bores and solitons that develop at its leading edge, and this type of sharp near-surface front spawned by a steepening bore, the distribution of energy between these features is unclear. Energy and momentum appear to be exchanged between these features in inhomogeneous and anisotropic ways; thus, fully understanding coastal energy or momentum budgets requires knowledge of both processes and how they operate together. Third, while we show evidence of both vertical and lateral shear instabilities developing at this front, there is a suggestive hint of interplay between them that cannot be fully assessed with these data. Future observational analysis or targeted numerical simulations may help disentangle some of these complexities.

The coexistence and intermingling of these two distinct features remind us that as students of turbulent flows we cannot restrict ourselves to the study of a single scale or type of ocean dynamics. This may be only one of many cases of intersections and interactions between nominally distinct phenomena that are yet to be appreciated.

\section{Dedication}

We dedicate this paper to our friend and colleague Sean Haney, who led this interdisciplinary collaboration (Fig. 12). Sean passed away in January of 2021, following several years of serious illness. Sean was a physical oceanographer at the Scripps Institution of Oceanography, where he was highly regarded both for his scientific insight and adventurous spirit. He completed his Ph.D. at University of Colorado Boulder in 2015 and made substantial contributions to our understanding of upper-ocean processes. He was extremely thoughtful and inquisitive, remembered by his colleagues as the person with whom to talk through challenging problems. Sean was a rare breed of oceanographer who was easily able to integrate complicated physical observations into equally complex theoretical frameworks. He was also a beloved shipmate, who brought a keen sensibility and a joyful, playful spirit to field work. Outside of work, Sean embraced every opportunity to explore and was often found surfing, mountain biking, climbing, skydiving, or camping. He was an avid participant in game nights, incredibly witty, and frequently the MVP of the trivia team. His kindness, brilliance, and spunk will forever be remembered. We miss you, Sean.

Acknowledgments. We are grateful for funding support from the Office of Naval Research under Grants N00014-15-1-2633, N00014-5-1-2631, N00014-15-1-2020, N00014-15-1-2617, and N00014-17-1-2171. Author Palóczy thanks the UC Ship Funds program for time on the R/V Sproul. We are grateful for the hard work and dedication of the captain and crew of the R/Vs Sally Ride, Oceanus, and Sproul. Authors Waterhouse and MacKinnon thank Sam Kelly for generous use of his VMP-250. We appreciate discussions with Roy Barkan about frontogenesis. Author Haney thanks Brian White and Karl Helfrich for helpful discussion elucidating gravity current regimes.

Data availability statement. The complete dataset from the Inner Shelf Dynamics Experiment, including the raw mooring, shipboard, and radar data required to reproduce the 

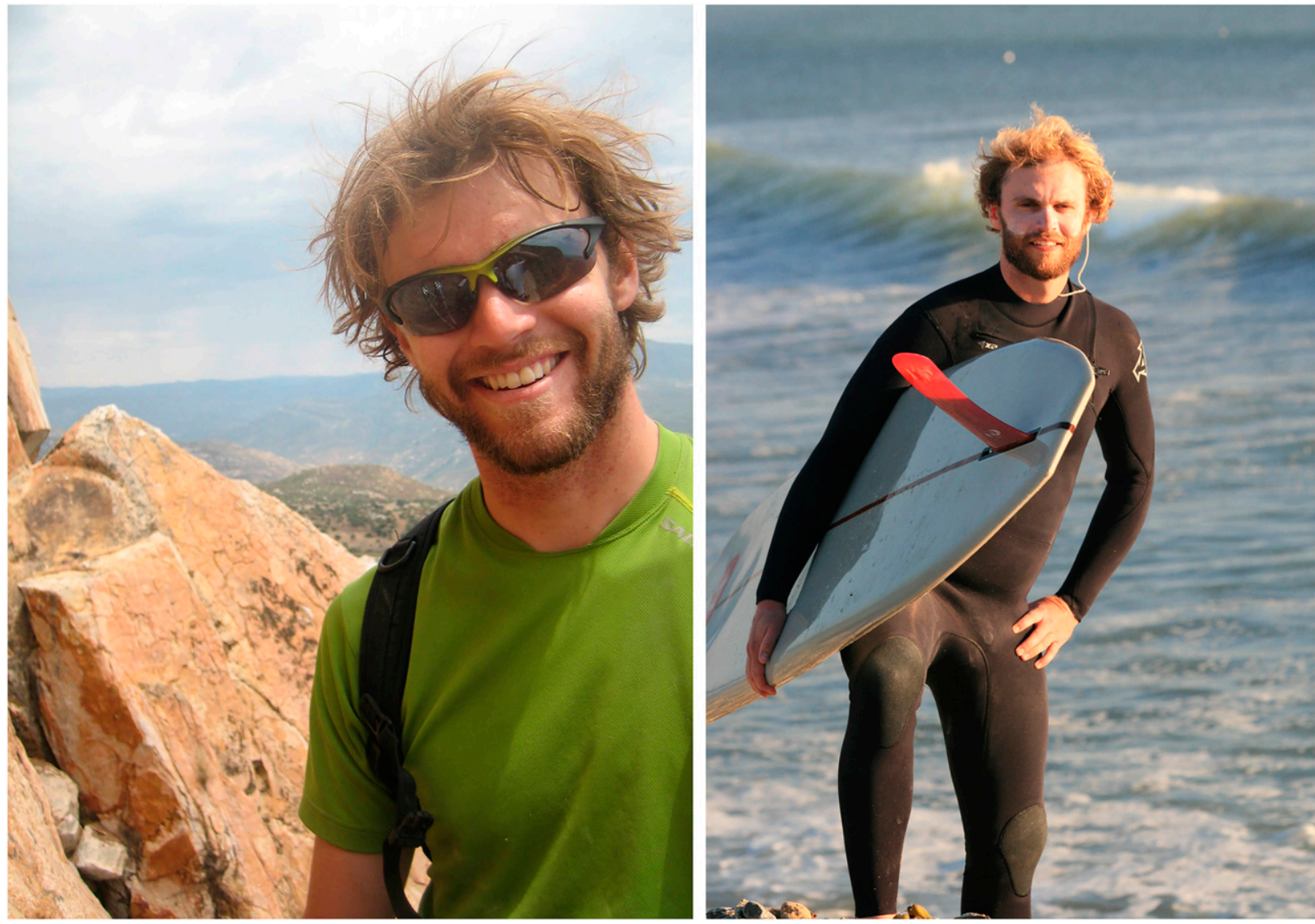

FIG. 12. Lead author Sean Haney, 1987-2021.

results in this paper, is archived online (https://doi.org/ 10.6075/J0WD3Z3Q).

\section{REFERENCES}

Adams, K., J. MacKinnon, A. J. Lucas, J. Nash, E. Shroyer, and J. T. Farrar, 2019: Multi-platform observations of small-scale lateral mixed layer variability in the northern Bay of Bengal. Deep-Sea Res. II, 168, 104629, https://doi.org/10.1016/j.dsr2.2019.07.017.

Barkan, R., M. J. Molemaker, K. Srinivasan, J. C. McWilliams, and E. A. D'Asaro, 2019: The role of horizontal divergence in submesoscale frontogenesis. J. Phys. Oceanogr., 49, 15931618, https://doi.org/10.1175/JPO-D-18-0162.1.

Becherer, J., J. N. Moum, J. A. Colosi, J. A. Lerczak, and J. M. McSweeney, 2020: Turbulence asymmetries in bottom boundary layer velocity pulses associated with onshore-propagating nonlinear internal waves. J. Phys. Oceanogr., 50, 2373-2391, https://doi.org/10.1175/JPO-D-19-0178.1.

Benjamin, T. B., 1966: Internal waves of finite amplitude and permanent form. J. Fluid Mech., 25, 241-270, https://doi.org/ 10.1017/S0022112066001630.

_, 1968: Gravity currents and related phenomena. J. Fluid Mech., 31, 209-248, https://doi.org/10.1017/S0022112068000133.

Boehm, A. B., N. S. Ismail, L. M. Sassoubre, and E. A. Andruszkiewicz, 2017: Oceans in peril: Grand challenges in applied water quality research for the 21st century. Environ. Eng. Sci., 34, 3-15, https:// doi.org/10.1089/ees.2015.0252.
Burchard, H., and Coauthors, 2008: Observational and numerical modeling methods for quantifying coastal ocean turbulence and mixing. Prog. Oceanogr., 76, 399-442, https://doi.org/ 10.1016/j.pocean.2007.09.005.

Chen, S.-N., C.-J. Chen, and J. A. Lerczak, 2020: On baroclinic instability over continental shelves: Testing the utility of Eadytype models. J. Phys. Oceanogr., 50, 3-33, https://doi.org/ 10.1175/JPO-D-19-0175.1.

Colosi, J. A., N. Kumar, S. H. Suanda, T. M. Freismuth, and J. H. MacMahan, 2018: Statistics of internal tide bores and internal solitary waves observed on the inner continental shelf off Point Sal, California. J. Phys. Oceanogr., 48, 123-143, https:// doi.org/10.1175/JPO-D-17-0045.1.

Fairall, C. W., E. F. Bradley, J. Hare, A. A. Grachev, and J. B. Edson, 2003: Bulk parameterization of air-sea fluxes: Updates and verification for the COARE algorithm. J. Climate, 16, 571-591, https:// doi.org/10.1175/1520-0442(2003)016<0571:BPOASF > 2.0.CO;2.

Geyer, W. R., A. C. Lavery, M. E. Scully, and J. H. Trowbridge, 2010: Mixing by shear instability at high Reynolds number. Geophys. Res. Lett., 37, L22607, https://doi.org/10.1029/ 2010GL045272.

Gill, A. E., 1982: Atmosphere-Ocean Dynamics. Academic Press, $662 \mathrm{pp}$.

Grimshaw, R., E. Pelinovsky, T. Talipova, and O. Kurkina, 2010: Internal solitary waves: Propagation, deformation and disintegration. Nonlinear Processes Geophys., 17, 633-649, https:// doi.org/10.5194/npg-17-633-2010. 
— C. Guo, K. Helfrich, and V. Vlasenko, 2014: Combined effect of rotation and topography on shoaling oceanic internal solitary waves. J. Phys. Oceanogr., 44, 1116-1132, https://doi.org/ 10.1175/JPO-D-13-0194.1.

Haller, M. C., D. A. Honegger, R. Pittman, A. O'Dea, and A. Simpson, 2019: Real-time marine radar observations of nearshore waves and flow structures from shore-based towers. IEEE/OES 12th Conf. on Current, Waves and Turbulence Measurement (CWTMA), San Diego, CA, IEEE, 1-7, https:// doi.org/10.1109/CWTM43797.2019.8955152.

Helfrich, K. R., W. Melville, and J. W. Miles, 1984: On interfacial solitary waves over slowly varying topography. J. Fluid Mech., 149, 305-317, https://doi.org/10.1017/S0022112084002664.

Holloway, P. E., E. Pelinovsky, T. Talipova, and B. Barnes, 1997: A nonlinear model of internal tide transformation on the Australian North West shelf. J. Phys. Oceanogr., 27, 871-896, https://doi.org/ 10.1175/1520-0485(1997)027<0871:ANMOIT>2.0.CO;2.

Hoskins, B. J., 1974: The role of potential vorticity in symmetric stability and instability. Quart. J. Roy. Meteor. Soc., 100, 480482, https://doi.org/10.1002/qj.49710042520.

- - , and F. P. Bretherton, 1972: Atmospheric frontogenesis models: Mathematical formulation and solutions. J. Atmos. Sci., 29, 11-37, https://doi.org/10.1175/15200469(1972)029<0011:AFMMFA > 2.0.CO;2.

Jurisa, J. T., J. D. Nash, J. N. Moum, and L. F. Kilcher, 2016: Controls on turbulent mixing in a strongly stratified and sheared tidal river plume. J. Phys. Oceanogr., 46, 2373-2388, https://doi.org/10.1175/JPO-D-15-0156.1.

Kelly, S., and J. D. Nash, 2010: Internal-tide generation and destruction by shoaling internal tides. Geophys. Res. Lett., 37, L23611, https://doi.org/10.1029/2010GL045598.

Kilcher, L. F., and J. D. Nash, 2010: Structure and dynamics of the Columbia River tidal plume front. J. Geophys. Res., 115, C05S90, https://doi.org/10.1029/2009JC006066.

Klingbeil, K., F. Lemarié, L. Debreu, and H. Burchard, 2018: The numerics of hydrostatic structured-grid coastal ocean models: State of the art and future perspectives. Ocean Modell., 125, 80-105, https://doi.org/10.1016/j.ocemod.2018.01.007.

Kumar, N., and Coauthors, 2021: The inner-shelf dynamics experiment. Bull. Amer. Meteor. Soc., 102, E1033-E1063, https:// doi.org/10.1175/BAMS-D-19-0281.1.

Lamb, K. G., 1994: Numerical experiments of internal wave generation by strong tidal flow across a finite amplitude bank edge. J. Geophys. Res., 99, 843-864, https://doi.org/10.1029/93JC02514.

— trapped cores. Phys. Fluids, 16, 4685-4695, https://doi.org/ 10.1063/1.1811551.

Lee, C.-Y., and R. C. Beardsley, 1974: The generation of long nonlinear internal waves in a weakly stratified shear flow. J. Geophys. Res., 79, 453-462, https://doi.org/10.1029/JC079i003p00453.

Lenain, L., and N. Pizzo, 2021: Modulation of surface gravity waves by internal waves. J. Phys. Oceanogr., 51, 2735-2748, https:// doi.org/10.1175/JPO-D-20-0302.1.

—, N. M. Statom, and W. K. Melville, 2019: Airborne measurements of surface wind and slope statistics over the ocean. J. Phys. Oceanogr., 49, 2799-2814, https://doi.org/10.1175/ JPO-D-19-0098.1.

Lentz, S. J., and M. R. Fewings, 2012: The wind-and wave-driven inner-shelf circulation. Annu. Rev. Mar. Sci., 4, 317-343, https://doi.org/10.1146/annurev-marine-120709-142745.

Lerczak, J., and Coauthors, 2019: Untangling a web of interactions where surf meets coastal ocean. Eos, Trans. Amer. Geophys. Union, 100, https://doi.org/10.1029/2019EO122141.
Lueck, R., 2013: Calculating the rate of dissipation of turbulent kinetic energy. Rockland Scientific International Tech. Note TN-028, 18 pp.

MacKinnon, J., and M. Gregg, 2003: Mixing on the late-summer New England shelf--Solibores, shear, and stratification. J. Phys. Oceanogr., 33, 1476-1492, https://doi.org/10.1175/ 1520-0485(2003)033<1476:MOTLNE > 2.0.CO;2.

Mahadevan, A., and A. Tandon, 2006: An analysis of mechanisms for submesoscale vertical motion at ocean fronts. Ocean Modell., 14, 241-256, https://doi.org/10.1016/j.ocemod.2006.05.006.

McSweeney, J. M., and Coauthors, 2020a: Observations of shoaling nonlinear internal bores across the central California inner shelf. J. Phys. Oceanogr., 50, 111-132, https://doi.org/10.1175/ JPO-D-19-0125.1.

_, and Coauthors, 2020b: Alongshore variability of shoaling internal bores on the inner shelf. J. Phys. Oceanogr., 50, 29652981, https://doi.org/10.1175/JPO-D-20-0090.1.

McWilliams, J. C., 2016: Submesoscale currents in the ocean. Proc. Roy. Soc. London, 472A, 20160117, https://doi.org/10.1098/ rspa.2016.0117.

_- 2021: Oceanic frontogenesis. Annu. Rev. Mar. Sci., 13, 227253, https://doi.org/10.1146/annurev-marine-032320-120725.

Melville, W. K., and K. R. Helfrich, 1987: Transcritical two-layer flow over topography. J. Fluid Mech., 178, 31-52, https:// doi.org/10.1017/S0022112087001101.

—, L. Lenain, D. R. Cayan, M. Kahru, J. P. Kleissl, P. Linden, and N. M. Statom, 2016: The modular aerial sensing system. J. Atmos. Oceanic Technol., 33, 1169-1184, https://doi.org/ 10.1175/JTECH-D-15-0067.1.

Michalke, A., 1964: On the inviscid instability of the hyperbolic tangent velocity profile. J. Fluid Mech., 19, 543-556, https:// doi.org/10.1017/S0022112064000908.

Moum, J. N., D. Farmer, W. Smyth, L. Armi, and S. Vagle, 2003a: Structure and generation of turbulence at interfaces strained by internal solitary waves propagating shoreward over the continental shelf. J. Phys. Oceanogr., 33, 2093-2112, https://doi.org/ 10.1175/1520-0485(2003)033<2093:SAGOTA > 2.0.CO;2.

—, D. M. Farmer, W. D. Smyth, L. Armi, and S. Vagle, 2003b: Structure and generation of turbulence at interfaces strained by internal solitary waves propagating shoreward over the continental shelf. J. Phys. Oceanogr., 33, 2093-2112, https://doi.org/ 10.1175/1520-0485(2003)033<2093:SAGOTA > 2.0.CO;2.

Nash, J. D., and J. N. Moum, 2005: River plumes as a source of large-amplitude internal waves in the coastal ocean. Nature, 437, 400-403, https://doi.org/10.1038/nature03936.

— , M. H. Alford, and E. Kunze, 2005: Estimating internal-wave energy fluxes in the ocean. J. Atmos. Oceanic Technol., 22, 1551-1570, https://doi.org/10.1175/JTECH1784.1.

Pham, H. T., and S. Sarkar, 2018: Ageostrophic secondary circulation at a submesoscale front and the formation of gravity currents. J. Phys. Oceanogr., 48, 2507-2529, https://doi.org/ 10.1175/JPO-D-17-0271.1.

Ramp, S. R., and Coauthors, 2004: Internal solitons in the northeastern South China Sea, part I: Sources and deep water propagation. IEEE J. Oceanic Eng., 29, 1157-1181, https:// doi.org/10.1109/JOE.2004.840839.

Rottman, J. W., and J. E. Simpson, 1989: The formation of internal bores in the atmosphere: A laboratory model. Quart. J. Roy. Meteor. Soc., 115, 941-963, https://doi.org/10.1002/qj.49711548809.

Scotti, A., and J. Pineda, 2004: Observation of very large and steep internal waves of elevation near the Massachusetts coast. Geophys. Res. Lett., 31, L22307, https://doi.org/ 10.1029/2004GL021052. 
R. C. Beardsley, and B. Butman, 2007: Generation and propagation of nonlinear internal waves in Massachusetts Bay. J. Geophys. Res., 112, C10001, https://doi.org/10.1029/ 2007JC004313.

—, R. Beardsley, B. Butman, and J. Pineda, 2008: Shoaling of nonlinear internal waves in Massachusetts Bay. J. Geophys. Res., 113, C08031, https://doi.org/10.1029/2008JC004726.

Shroyer, E., J. Moum, and J. Nash, 2009: Observations of polarity reversal in shoaling nonlinear internal waves. J. Phys. Oceanogr., 39, 691-701, https://doi.org/10.1175/2008JPO3953.1.

$\_, \ldots$, and _ 2010: Energy transformations and dissipation of nonlinear internal waves over New Jersey's continental shelf. Nonlinear Processes Geophys., 17, 345-360, https:// doi.org/10.5194/npg-17-345-2010.

Smyth, W. D., and J. N. Moum, 2012: Ocean mixing by KelvinHelmholtz instability. Oceanography, 25, 140-149, https:// doi.org/10.5670/oceanog.2012.49.

Solodoch, A., J. M. Molemaker, K. Srinivasan, M. Berta, L. Marie, and A. Jagannathan, 2020: Observations of shoaling density current regime changes in internal wave interactions. J. Phys. Oceanogr., 50, 1733-1751, https://doi.org/10.1175/JPO-D-19-0176.1.

Stastna, M., and K. G. Lamb, 2002: Large fully nonlinear internal solitary waves: The effect of background current. Phys. Fluids, 14, 2987-2999, https://doi.org/10.1063/1.1496510.

Stone, P. H., 1966: On non-geostrophic baroclinic stability. J. Atmos. Sci., 23, 390-400, https://doi.org/10.1175/15200469(1966)023<0390:ONGBS > 2.0.CO;2.

Suanda, S. H., and J. A. Barth, 2015: Semidiurnal baroclinic tides on the central Oregon inner shelf. J. Phys. Oceanogr., 45, 2640-2659, https://doi.org/10.1175/JPO-D-14-0198.1.

Thomas, J., J. Lerczak, and J. Moum, 2016: Horizontal variability of high-frequency nonlinear internal waves in Massachusetts Bay detected by an array of seafloor pressure sensors. J. Geophys. Res. Oceans, 121, 5587-5607, https://doi.org/ 10.1002/2016JC011866.
Thomas, L. N., 2017: On the modifications of near-inertial waves at fronts: Implications for energy transfer across scales. Ocean Dyn., 67, 1335-1350, https://doi.org/10.1007/s10236-017-1088-6.

Vlasenko, V., and K. Hutter, 2002: Numerical experiments on the breaking of solitary internal waves over a slope-shelf topography. J. Phys. Oceanogr., 32, 1779-1793, https://doi.org/ 10.1175/1520-0485(2002)032<1779:NEOTBO > 2.0.CO;2.

— amplitude internal waves. J. Geophys. Res., 112, C11018, https://doi.org/10.1029/2007JC004107.

Walter, R. K., M. Stastna, C. B. Woodson, and S. G. Monismith, 2016: Observations of nonlinear internal waves at a persistent coastal upwelling front. Cont. Shelf Res., 117, 100-117, https:// doi.org/10.1016/j.csr.2016.02.007.

Wang, T., R. Barkan, J. C. McWilliams, and M. J. Molemaker, 2021: Structure of submesoscale fronts of the Mississippi River plume. J. Phys. Oceanogr., 51, 1113-1131, https://doi.org/ 10.1175/JPO-D-20-0191.1.

Warner, S. J., R. M. Holmes, E. H. M. Hawkins, M. S. HoeckerMartínez, A. C. Savage, and J. N. Moum, 2018: Buoyant gravity currents released from tropical instability waves. J. Phys. Oceanogr., 48, 361-382, https://doi.org/10.1175/JPO-D-17-0144.1.

Waterhouse, A. F., and Coauthors, 2020: Observations and model simulations from the Inner-Shelf Dynamics Experiment (ISDE). UC San Diego Library Digital Collections, https:// doi.org/10.6075/J0WD3Z3Q.

White, B. L., and K. R. Helfrich, 2008: Gravity currents and internal waves in a stratified fluid. J. Fluid Mech., 616, 327-356, https://doi.org/10.1017/S0022112008003984.

- , and - 2012: A general description of a gravity current front propagating in a two-layer stratified fluid. J. Fluid Mech., 711, 545-575, https://doi.org/10.1017/jfm.2012.409.

$\longrightarrow$, and - 2013: Rapid gravitational adjustment of horizontal shear flows. J. Fluid Mech., 721, 86-117, https://doi.org/ 10.1017/jfm.2013.41. 